University of Nebraska - Lincoln

DigitalCommons@University of Nebraska - Lincoln

Papers in Natural Resources

Natural Resources, School of

2015

\title{
Modeling actual evapotranspiration with routine meteorological variables in the data-scarce region of the Tibetan Plateau: Comparisons and implications
}

Ning Ma

Chinese Academy of Sciences, Beijing, China

Yinsheng Zhang

Chinese Academy of Sciences, Beijing, China

Chong-Yu Xu

Chinese Academy of Sciences, Beijing, China

Jozsef Szilagyi

Budapest University of Technology and Economics, jszilagyi1@unl.edu

Follow this and additional works at: http://digitalcommons.unl.edu/natrespapers

Part of the Natural Resources and Conservation Commons, Natural Resources Management and Policy Commons, and the Other Environmental Sciences Commons

Ma, Ning; Zhang, Yinsheng; Xu, Chong-Yu; and Szilagyi, Jozsef, "Modeling actual evapotranspiration with routine meteorological variables in the data-scarce region of the Tibetan Plateau: Comparisons and implications" (2015). Papers in Natural Resources. 605. http://digitalcommons.unl.edu/natrespapers/605

This Article is brought to you for free and open access by the Natural Resources, School of at DigitalCommons@University of Nebraska - Lincoln. It has been accepted for inclusion in Papers in Natural Resources by an authorized administrator of DigitalCommons@University of Nebraska - Lincoln. 


\section{Journal of Geophysical Research: Biogeosciences}

\section{RESEARCH ARTICLE \\ 10.1002/2015JG003006 \\ Key Points: \\ - Routine meteorological variables aid $\mathrm{ET}_{\mathrm{a}}$ estimation in data-scarce region \\ Modeling actual evapotranspiration with routine meteorological variables in the data-scarce region of the Tibetan Plateau: Comparisons and implications}

- CR and Penman-Monteith approaches were evaluated against measured $\mathrm{ET}_{\mathrm{a}}$ in TP

- Nonlinear-CR model is preferred when measured $\mathrm{ET}_{\mathrm{a}}$ is unavailable

Correspondence to:

Y. Zhang,

yszhang@itpcas.ac.cn

Citation:

Ma, N., Y. Zhang, C.-Y. Xu, and J. Szilagyi (2015), Modeling actual evapotranspiration with routine meteorological variables in the data-scarce region of the Tibetan Plateau: Comparisons and implications, J. Geophys. Res. Biogeosci., 120, 1638-1657, doi:10.1002/2015JG003006

Received 5 APR 2015 Accepted 20 JUL 2015 Accepted article online 23 JUL 2015 Published online 22 AUG 2015

Used by permission.

(c)2015. American Geophysical Union. All Rights Reserved.

\author{
Ning Ma ${ }^{1,2}$, Yinsheng Zhang ${ }^{1,3}$, Chong-Yu Xu ${ }^{1,4}$, and Jozsef Szilagyi ${ }^{5,6}$ \\ ${ }^{1}$ Key Laboratory of Tibetan Environment Changes and Land Surface Processes, Institute of Tibetan Plateau Research, \\ Chinese Academy of Sciences, Beijing, China, ${ }^{2}$ University of Chinese Academy of Sciences, Beijing, China, ${ }^{3}$ CAS Center for \\ Excellence in Tibetan Plateau Earth Sciences, Beijing, China, ${ }^{4}$ Department of Geosciences, University of Oslo, Oslo, Norway, \\ ${ }^{5}$ Department of Hydraulic and Water Resources Engineering, Budapest University of Technology and Economics, Budapest, \\ Hungary, ${ }^{6}$ School of Natural Resources, University of Nebraska-Lincoln, Lincoln, Nebraska, USA
}

Abstract Quantitative estimation of actual evapotranspiration ( $\mathrm{ET}_{\mathrm{a}}$ ) by in situ measurements and mathematical modeling is a fundamental task for physical understanding of $\mathrm{ET}_{\mathrm{a}}$ as well as the feedback mechanisms between land and the ambient atmosphere. However, the $\mathrm{ET}_{\mathrm{a}}$ information in the Tibetan Plateau (TP) has been greatly impeded by the extremely sparse ground observation network in the region. Approaches for estimating $\mathrm{ET}_{\mathrm{a}}$ solely from routine meteorological variables are therefore important for investigating spatiotemporal variations of $\mathrm{ET}_{\mathrm{a}}$ in the data-scarce region of the TP. Motivated by this need, the complementary relationship (CR) and Penman-Monteith approaches were evaluated against in situ measurements of $\mathrm{ET}_{\mathrm{a}}$ on a daily basis in an alpine steppe region of the TP. The former includes the Nonlinear Complementary Relationship (Nonlinear-CR) as well as the Complementary Relationship Areal Evapotranspiration (CRAE) models, while the latter involves the Katerji-Perrier and the Todorovic models. Results indicate that the Nonlinear-CR, CRAE, and Katerji-Perrier models are all capable of efficiently simulating daily $\mathrm{ET}_{a}$, provided their parameter values were appropriately calibrated. The Katerji-Perrier model performed best since its site-specific parameters take the soil water status into account. The Nonlinear-CR model also performed well with the advantage of not requiring the user to choose between a symmetric and asymmetric CR. The CRAE model, even with a relatively low Nash-Sutcliffe efficiency (NSE) value, is also an acceptable approach in this data-scarce region as it does not need information of wind speed and ground surface conditions. In contrast, application of the Todorovic model was found to be inappropriate in the dry regions of the TP due to its significant overestimation of $\mathrm{ET}_{\mathrm{a}}$ as it neglects the effect of water stress on the bulk surface resistance. Sensitivity analysis of the parameter values demonstrated the relative importance of each parameter in the corresponding model. Overall, the Nonlinear-CR model is recommended in the absence of measured $\mathrm{ET}_{\mathrm{a}}$ for local calibration of the model parameter values.

\section{Introduction}

Actual evapotranspiration ( $\mathrm{ET}_{\mathrm{a}}$ ) is a key component in global water and energy cycles. On average, more than $60 \%$ of global land precipitation is returned to the atmosphere through terrestrial $\mathrm{ET}_{\mathrm{a}}$ [Oki and Kanae, 2006]. $\mathrm{ET}_{\mathrm{a}}$ as latent heat flux consumes roughly $50 \%$ of the solar radiation absorbed by the Earth's surface [Trenberth et al., 2009]. Therefore, quantifying it is a fundamental task for elucidating how the hydrological cycle responds to climate change. However, investigating $\mathrm{ET}_{\mathrm{a}}$ is challenging because of its complex interactions across the soil-vegetation-atmosphere interface [Katul et al., 2012; Matheny et al., 2014; Zhang et al., 2014]. Historically, $\mathrm{ET}_{\mathrm{a}}$ was related (via linear or nonlinear scaling with soil moisture) to direct measurements of its conceived maximum value, i.e., pan evaporation [see Brutsaert, 2013, and references therein]. However, neither water-limited nor energy-limited land surface $\mathrm{ET}_{\mathrm{a}}$ acts as pan evaporation [Brutsaert, 1982]. With recent advances in high-frequency response instrumentation and data storage, a better understanding of $\mathrm{ET}_{\mathrm{a}}$ from various land covers has been achieved through the use of in situ flux observations [e.g., Baldocchi et al., 2004; Fischer et al., 2013; Ma et al., 2014; Mackay et al., 2007; Wilson and Baldocchi, 2000]. These studies have significantly contributed to our knowledge of regional hydrological regimes and their complex feedback mechanisms between land and the ambient atmosphere [Baldocchi, 2014]. 
With a total area of roughly $2.5 \times 10^{6} \mathrm{~km}^{2}$ and an average elevation higher than $4000 \mathrm{~m}$ above sea level (asl), the Tibetan Plateau (TP) is also known as the "Third Pole" of the Earth [Qiu, 2008]. It has been widely accepted that both sensible and latent heat release from the TP can intensify monsoon circulation and may also influence the weather and climate of Eastern Asia [Li and Yanai, 1996; Ye and Wu, 1998]. In addition, the TP has experienced a much higher rate of warming in comparison with similar Northern Hemisphere latitudes over recent decades [Yang et al., 2011; Zhong et al., 2011]. Interestingly, the response of spring phenology (e.g., the green-up date) of alpine grassland to warming varied significantly among the different areas of the TP. For example, recent investigations have shown that the green-up date of certain alpine grasslands did not significantly advance [Shen et al., 2013, 2014] despite an obvious increase in spring temperature. Since most alpine grasslands in the TP are characterized as arid or semiarid [Yin et al., 2013a; Zheng et al., 2013], the interplay between precipitation and $\mathrm{ET}_{\mathrm{a}}$ may therefore affect the vegetation phenology to a large extent. However, knowledge of $\mathrm{ET}_{\mathrm{a}}$ in the TP has been greatly hindered by the lack of in situ observations.

In the past decades, a few land surface process experiments (e.g., the Global Energy and Water Cycle Experiment-Asian Monsoon Experiment-Tibet [Koike, 1999] and the Coordinated Energy and Water Cycle Observation Project-Asia and Australia Monsoon Project in Tibet [Koike, 2004]) using a variety of instruments (e.g., eddy covariance and/or Bowen ratio energy balance systems) were conducted at several sites of the TP to improve upon the scarcity of land surface energy and water flux data. Unfortunately, the majority of these experiments were carried out for relatively short periods of the summer since the environment is too harsh to maintain continuous long-term operation of advanced instruments. Thus, long time series of $\mathrm{ET}_{\mathrm{a}}$ are still urgently needed. While it is true that recent improvements in land surface models (LSMs) have offered an opportunity for obtaining long-term $\mathrm{ET}_{\mathrm{a}}$ data in the TP [Yang et al., 2011; Zhou and Huang, 2012], the performance of LSMs depends on the detail and accuracy of the input parameter values (e.g., soil and vegetation information), a challenge for the TP because of its large area and high altitude. Besides, the applicability of the default parameterization schemes for some key physical processes in LSMs in high-altitude dry environments is still uncertain. For example, K. Yang et al. [2009] reported a significant bias in latent heat flux simulated by the SiB2, CoLM, and Noah models due to their failure in the correct parameterization of soil moisture dynamics and soil surface resistance in arid and semiarid regions of TP. In other words, substantial improvements in soil hydrology parameterization are needed before LSMs may become capable of reliable $\mathrm{ET}_{\mathrm{a}}$ simulations in the TP, as has also been highlighted by Hong and Kim [2010]. Alternatively, there are more than 70 conventional meteorological stations run by the China Meteorological Administration (CMA) in the TP. Most of them have started routine meteorological observations (e.g., air temperature, actual vapor pressure, wind speed, sunshine duration, and soil temperature) as early as the 1960s. Therefore, with appropriate estimation methods that exploit these routine meteorological data, it may be possible to quantify the long-term $\mathrm{ET}_{\mathrm{a}}$ variations within the TP, which would be highly valuable in an area (and in other similar regions) where direct measurements of $\mathrm{ET}_{\mathrm{a}}$ are extremely sparse.

Several methods exist to estimate $\mathrm{ET}_{\mathrm{a}}$ using only routine meteorological observations [McMahon et al., 2013; Rigden and Salvucci, 2015; Drexler et al., 2004]. Among them, the complementary relationship (CR) approach of Bouchet [1963] has been shown to be a viable strategy [Crago and Qualls, 2013; Szilagyi and Jozsa, 2008]. Various models based on the $C R$ have been proposed over the past decades. For example, the well-known Advection-Aridity (AA) model of Brutsaert and Stricker [1979] has been extensively used in many regions for obtaining long-term $\mathrm{ET}_{\mathrm{a}}$ [e.g., Liu et al., 2006; Ozdogan and Salvucci, 2004; Szilagyi et al., 2001, 2009; Wang et al., 2011]. Recently Han et al. [2012] improved the original AA model by introducing a nonlinear function to represent the relationship between $\mathrm{ET}_{\mathrm{a}}$ and the potential evapotranspiration rate $\left(\mathrm{ET}_{\mathrm{p}}\right)$. This new Nonlinear-CR model was shown to be realistic over a wide range of land surface aridity [Han et al., 2014a, 2014b]. Additionally, Morton [1983] proposed a novel technique called Complementary Relationship Areal Evapotranspiration (CRAE) model for estimating $\mathrm{ET}_{\mathrm{a}}$ based on the $\mathrm{CR}$, but without the need of wind speed data as input.

On the other hand, the Penman-Monteith approach [Monteith, 1965] is regarded as another effective way to estimate $\mathrm{ET}_{\mathrm{a}}$, and it has been successfully used for different land covers [e.g., Katerji et al., 2011; Rana and Katerji, 2008; Shi et al., 2008]. However, the main difficulty of utilizing the Penman-Monteith approach involves the determination of one of its key inputs, namely, the bulk surface resistance $\left(r_{s}\right)$, for different climatic, vegetation, and soil water conditions [Shuttleworth, 2007; Wang and Dickinson, 2012]. This is because 


\section{AGU Journal of Geophysical Research: Biogeosciences 10.1002/2015JG003006}

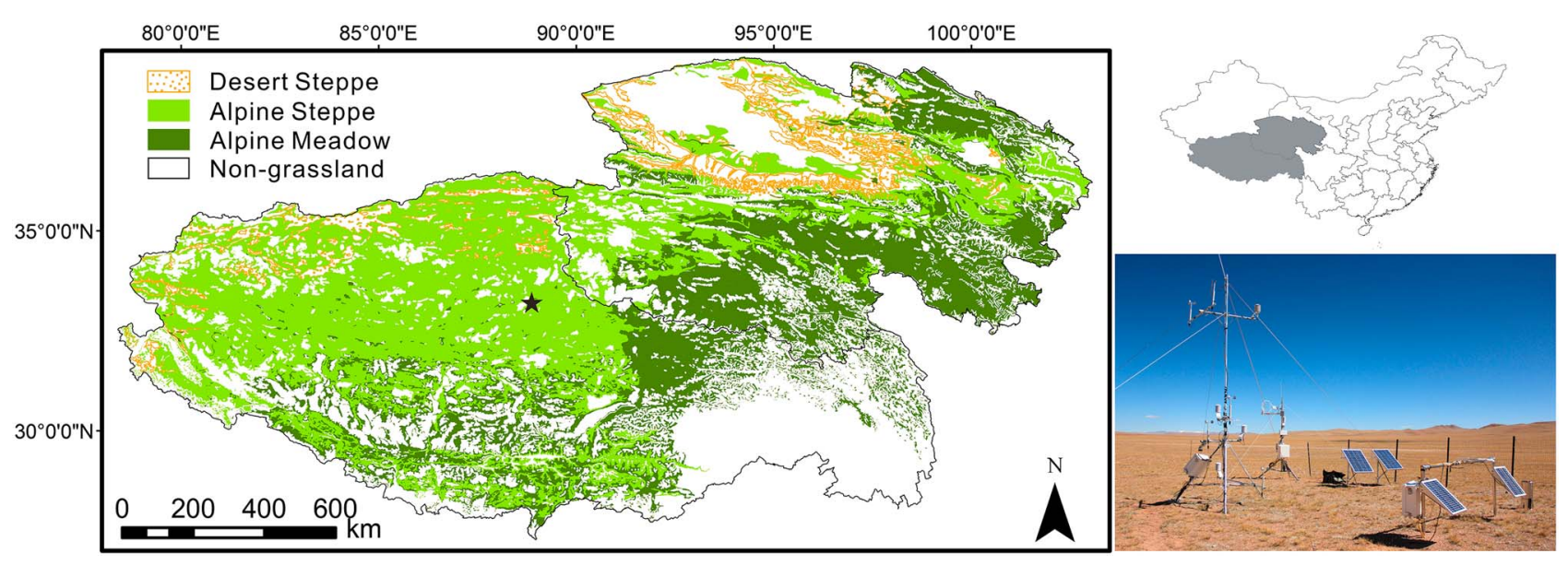

Figure 1. The geographical setting of the study area (marked by a star) and a photograph of the in situ flux and energy measurements site in the Tibetan Plateau. The grassland classifications are based on Y. Yang et al. [2009].

$r_{\mathrm{s}}$ varies widely with changes of actual environmental and biological conditions [Baldocchi et al., 1997; Brümmer et al., 2012; Wilson and Baldocchi, 2000]. Therefore, Katerji and Perrier [1983] proposed a method (the Katerji-Perrier model) that considers the phenological stage and soil water status to solve for the time variant $r_{\mathrm{s}}$ with the help of another parameter called the "critical resistance." Unfortunately, the parameter values in the Katerji-Perrier model cannot be universally calibrated because they appear to vary markedly among different ecosystems [Katerji and Rana, 2006; Rana et al., 2005; Shi et al., 2008]. To overcome this difficulty, Todorovic [1999] established a universal scheme (the Todorovic model) for acquiring $r_{s}$ under a given weather condition.

Considering that there are two different approaches ( $C R$ and Penman-Monteith based) that require only routine meteorological variables for the estimation of $\mathrm{ET}_{a}$, it is desirable to evaluate and compare their performance within the hydroclimatologically important, but sparsely instrumented, TP region. Moreover, knowledge of selecting the most appropriate model under different data availability scenarios is needed since (i) routine meteorological data may not be available in every site and/or (ii) direct $\mathrm{ET}_{\mathrm{a}}$ measurements to calibrate the parameter values for a given model may not be available in some ecosystems. Via the in situ Bowen ratio energy balance (BREB) measurements of $\mathrm{ET}_{\mathrm{a}}$ within a typical alpine steppe ecosystem of the TP, the objectives of the present study were to (1) compare the effectiveness of the different models requiring only routine meteorological variables for estimating $\mathrm{ET}_{\mathrm{a}}$ with default and calibrated parameters values, (2) present how the models differ in interpretation of the variability of $\mathrm{ET}_{\mathrm{a}}$ in the study region, and (3) provide recommendations for model selection in the data-scarce region of the TP under different data availability conditions.

\section{Materials and Methods}

\subsection{Study Area}

The in situ observation site (Figure 1) is a representative of the alpine steppe ecosystem, which accounts for approximately one third of the TP area. Located in central TP at an elevation of $4947 \mathrm{~m}$ asl, this site is generally homogeneous with a fetch larger than a kilometer for the prevailing wind direction. The region is characterized by a frigid semiarid climate [Zheng et al., 2013]. Climate data (1981-2010) at the nearest CMA station at Bange ( $4719 \mathrm{~m}$ asl), $230 \mathrm{~km}$ southeast of the in situ observation site, show that the mean annual temperature is $-3.3^{\circ} \mathrm{C}$, with monthly averages of $-10.1^{\circ} \mathrm{C}$ for January and $9.1^{\circ} \mathrm{C}$ for July, and annual precipitation of $333 \mathrm{~mm}$, falling mainly between June and September. Annual potential evapotranspiration rate is approximately $1000 \mathrm{~mm}$ [Wang et al., 2013]. The soil at the observation site is predominantly sandy loam composed of $0.7 \%$ clay, $22.5 \%$ silt, and $76.7 \%$ sand. The bulk density of the surface layer $(0-5 \mathrm{~cm})$ is $1.29 \mathrm{~g} \mathrm{~cm}^{-3}$. The dominant vegetation types are cold-xerophytic $\mathrm{C} 3$ grasses such as Stipa purpurea and Carex moorcroftii. Mean canopy height and coverage in the growing season are $0.03 \mathrm{~m}$ and $30 \%$, respectively. The peak leaf area index and the aboveground biomass are estimated as approximately 0.5 and $50.1 \mathrm{~g} \mathrm{~m}^{-2}$, respectively [Y. Yang et al., 2009]. 


\subsection{Instrumentation}

An automatic climate observation system was installed at the site in September 2011 (Figure 1). Specifically, air temperature/humidity (HMP45C, Vaisala Inc., Finland) and wind speed (010C-1, MetOne Inc., USA) were measured at heights of $0.7,1.5,2$, and $4 \mathrm{~m}$. Wind direction (020C-1, MetOne Inc., USA) was measured at $4 \mathrm{~m}$ aboveground. Downward and upward short- and long-wave radiation (CNR4, Kipp\&Zonen Inc., Netherlands) were measured at a height of $0.7 \mathrm{~m}$. Soil temperatures (109, Campbell Scientific Inc., USA) were measured at depths of 0 and $0.05 \mathrm{~m}$. A soil heat flux plate (HFP01SC, Hukseflux, Netherlands) was inserted at $0.03 \mathrm{~m}$ below the surface. All the above observations were recorded as $10 \mathrm{~min}$ averages from approximately $4 \mathrm{~s}$ readings, and data were stored in a CR1000 data logger (Campbell Scientific Inc., USA). Rainfall was measured with a tipping-bucket rain gauge (SML-3, Shanghai Meteorological Instrument Inc., China). An eddy covariance (EC) system, comprising an open-path infrared $\mathrm{CO}_{2} / \mathrm{H}_{2} \mathrm{O}$ gas analyzer (LI-7500A, LI-COR Inc., USA) and a three-dimensional sonic anemometer (CSAT3, Campbell Scientific Inc., USA), was installed at the end of September 2013. The installation height of the EC was $2.47 \mathrm{~m}$. The EC sampled at $10 \mathrm{~Hz}$ and data were stored in a CR3000 data logger (Campbell Scientific Inc., USA).

\subsection{Postprocessing Measured Data}

The raw 10 min mean meteorological data were first aggregated to half-hourly average values. The soil temperature integral method [Oliphant et al., 2004] was used to calculate soil heat storage between 0 and $0.03 \mathrm{~m}$ depth. By summing the soil heat flux values measured at depth of $0.03 \mathrm{~m}$, the soil heat flux into the ground surface could be obtained. The Bowen ratio was derived using air temperature and humidity values at 0.7 and $4 \mathrm{~m}$, respectively. Finally, $30 \mathrm{~min}$ latent heat fluxes $(\lambda E)$ were derived using the Bowen ratio energy balance (BREB) method [Allen et al., 2011]. Three quality control processes were implemented involving data removal when (i) $\lambda E>700 \mathrm{~W} \mathrm{~m}^{-2}$ or $\lambda E<-200 \mathrm{~W} \mathrm{~m}^{-2}$, (ii) the Bowen ratio fell between -1.3 and -0.7 [Kurc and Small, 2004; Unland et al., 1996], and (iii) values exceeded the Perez et al. [1999] criteria for determining the suitable sign of $\lambda E$. This resulted in data gaps of $20.5 \%, 23.4 \%$, and $21.8 \%$ for the 30 min BREB-measured $\lambda E$ values in 2012 (1 July to 30 September), 2013 (1 July to 30 September) and 2014 (1 August to 30 September), respectively. All BREB-derived $\lambda E$ gaps in data resulted only from quality control processes, and they mainly occurred around sunrise and sunset, and occasionally at nightfall.

The EC data in the present research are only available from 1 August to 30 September 2014. They are used for comparison with the BREB-derived $\lambda E$ data in the corresponding period to judge the reliability of the BREB method. Be specific, the raw high-frequency EC data were processed by the EddyPro 4.2 software (LI-COR Inc., USA). It implemented the removal of spikes, tilt correction using double rotation, detrending with the block average method, time lag compensation, sonic virtual temperature correction, spectral correction, and the Webb-Pearman-Leuning correction [see Burba, 2013, and references therein]. Finally, the $\lambda E$ values were calculated over $30 \mathrm{~min}$ periods. The resulting half-hourly EC-measured $\lambda E$ values were subsequently quality controlled to exclude (i) data obtained during rain events and (ii) data with quality flags of " 2 " from the steady state and integral turbulence characteristics tests [Mauder and Foken, 2004]. Exclusion eventually comprised $25.2 \%$ of the total number of EC-derived $\lambda E$ values, and all gaps arose only from quality control processes.

Considering the primary purpose of the present study is evaluating the models on a daily basis (see section 2.5 ), the half-hourly $\lambda E$ gaps needed to be filled to obtain daily $\mathrm{ET}_{\mathrm{a}}$ values. Since continuous halfhourly shortwave downward radiation, air temperature, and vapor pressure deficit data were all available, we applied the marginal distribution sampling (MDS) technique of Reichstein et al. [2005], an enhancement of the traditional look-up table method (the standardized energy flux gap-filling strategy of the flux community [Falge et al., 2001]) that takes both the covariation of fluxes with meteorological variables and the temporal autocorrelation of the fluxes into account, to fill all above mentioned half-hourly $\lambda E$ gaps. Besides, the data from 1 July to 30 September 2013 (i.e., the validation period, see section 2.5) were selected to test the accuracy of the MDS method. It started with the $23.4 \%$ original gaps to which randomly generated additional artificial gaps were added until the total $\lambda E$ gaps accounted for $40.4 \%$ of all data. By applying the MDS gap-filling method again, the measured and the so-filled half-hourly $\lambda E$ values of the artificial gaps could be compared. The result shows that the mean absolute difference is $22.7 \mathrm{~W} \mathrm{~m}^{-2}$. It entails that the gap-filling procedure would lead to a maximum uncertainty of $\pm 0.2 \mathrm{~mm} \mathrm{~d}^{-1}$ for the measured daily $\mathrm{ET}_{\mathrm{a}}$ rates during July-September 2013 provided that the original $23.4 \%$ half-hourly gaps are evenly distributed in each day. 
It has long been recognized that systematic errors such as wind-induced undercatch, wetting, and evaporation losses in precipitation measurements affect all types of precipitation gauges [Yang et al., 2005; Ye et al., 2004]. Hence, the original records of the tipping-bucket rain gauge were corrected using the scheme of $Y e$ et al. [2004] to remove such bias in precipitation data.

\subsection{Model Descriptions}

As has been mentioned previously, four models were selected for analysis: the Nonlinear-CR, CRAE, Katerji-Perrier, and Todorovic models. Ma et al. [2015] recently demonstrated that the AA model [Brutsaert and Stricker, 1979; Szilagyi et al., 2009] when implemented via local calibration for potential and wet environment evapotranspiration rates indeed leads to a symmetric $C R$, thereby performing well in modeling $\mathrm{ET}_{\mathrm{a}}$ within the TP. It would be therefore interesting to evaluate how other CR approach-based models, with different definitions and calibration procedures, perform in the data-scarce region of TP. In the present study, we chose CRAE, which is a predefined symmetric CR-based model by Morton [1983], as well as the NonlinearCR model [Han et al., 2012] which does not need any predetermination of the existence/absence of the symmetry in the CR.

In terms of the Penman-Monteith approach, the Katerji-Perrier model requires careful calibration of sitedependent parameter values [Katerji et al., 2011], whereas the Todorovic is a calibration-free model claimed to be applicable anywhere in the world [Todorovic, 1999]. Both the Katerji-Perrier and Todorovic models have been tested in a variety of ecosystems for obtaining their time-varying $r_{\mathrm{s}}$, but their effectiveness remains a controversial issue. The studies of Steduto et al. [2003] and Lecina et al. [2003] involving irrigated farmlands in Europe have demonstrated that the Todorovic model is superior to the Katerji-Perrier model because the former does not require site-specific calibration. However, recent researches in water-limited areas have reported that the Todorovic model can overestimate ETa significantly [Katerji et al., 2011; Shi et al., 2008]. Consequently, a new comparison of the two models is needed to shed light on their applicability in highaltitude regions such as the TP.

\subsubsection{CR Approach}

The complementary relationship of evapotranspiration by Bouchet [1963] can be expressed as a simple equation, i.e.,

$$
\mathrm{ET}_{\mathrm{p}}-\mathrm{ET}_{\mathrm{w}}=\eta\left(\mathrm{ET}_{\mathrm{w}}-\mathrm{ET}_{\mathrm{a}}\right)
$$

where $\mathrm{ET}_{\mathrm{w}}$ is the so-called wet environment evapotranspiration rate resulting from a uniform wet surface of regional extent. For such a homogeneous surface with ample moisture, $\mathrm{ET}_{\mathrm{a}}=\mathrm{ET}_{\mathrm{p}}=\mathrm{ET}_{\mathrm{w}}$. With limited water availability that dries the ambient air, $\mathrm{ET}_{\mathrm{a}}$ decreases, and the energy that would have been consumed by $\mathrm{ET}_{\mathrm{a}}$ thus becomes sensible heat that warms the atmospheric boundary layer, thereby causing $\mathrm{ET}_{\mathrm{p}}$ to increase. $\eta$ is a coefficient that depicts the proportion of the sensible heat that increases $\mathrm{ET}_{\mathrm{p}}$. A value of $\eta=1$ indicates that $\mathrm{ET}_{\mathrm{a}}$ decreases by the same amount as $\mathrm{ET}_{\mathrm{p}}$ increases and is indicative of a symmetric CR. If $E T_{a}$ decreases at a different rate as $\mathrm{ET}_{\mathrm{p}}$ increases, $\eta$ is not equal to unity, indicative of an asymmetric $\mathrm{CR}$ (see the schematic representation of symmetric and asymmetric CR in Ma et al. [2015]).

\subsubsection{Nonlinear-CR Model}

According to Brutsaert and Stricker [1979], the $\mathrm{ET}_{\mathrm{p}}$ term can generally be defined by the Penman [1948] method, which involves two terms, namely, the radiation term, $E T_{\text {rad, }}$ and the aerodynamic term, $\mathrm{ET}_{\text {aero, }}$ i.e.,

$$
\mathrm{ET}_{\mathrm{p}}=\mathrm{ET}_{\text {rad }}+\mathrm{ET}_{\text {aero }}
$$

where

$$
\begin{aligned}
\mathrm{ET}_{\text {rad }} & =\frac{\Delta}{\Delta+\gamma} \frac{R \mathrm{n}-G}{\lambda} \\
\mathrm{ET}_{\text {aero }} & =\frac{1}{\lambda} \frac{\gamma}{\Delta+\gamma} f(U) D
\end{aligned}
$$

Here $R_{\mathrm{n}}$ is net radiation $\left(\mathrm{W} \mathrm{m}{ }^{-2}\right), G$ the soil heat flux into the ground surface $\left(\mathrm{W} \mathrm{m}^{-2}\right), \Delta$ the slope of the saturation vapor pressure curve at air temperature $\left(\mathrm{kPa}{ }^{\circ} \mathrm{C}^{-1}\right), \gamma$ the psychrometric constant $\left(\mathrm{kPa}{ }^{\circ} \mathrm{C}^{-1}\right), \lambda$ the latent heat of vaporization $\left(\mathrm{J} \mathrm{kg}^{-1}\right)$, and $D$ the vapor pressure deficit $(\mathrm{kPa})$. The so-called wind function is $f(U)$, which was originally calibrated by Penman [1948] using a linear relationship with horizontal mean 
wind speed. However, another universal form which involves the aerodynamic resistance $\left(r_{\mathrm{a}}\right)$ has been recommended [Crago et al., 2010; Han et al., 2012] as

$$
f(U)=\frac{\rho C_{\mathrm{p}} / r_{\mathrm{a}}}{\gamma}
$$

where $\rho$ is the air density at constant pressure $\left(\mathrm{kg} \mathrm{m}^{-3}\right)$ and $C_{\mathrm{p}}$ is the specific heat of air $\left(\mathrm{J} \mathrm{kg}^{-1} \mathrm{~K}^{-1}\right) \cdot r_{\mathrm{a}}\left(\mathrm{s} \mathrm{m}^{-1}\right)$ can be calculated using the Monin-Obukhov similarity theory [Brutsaert, 1982], i.e.,

$$
r_{\mathrm{a}}=\frac{\left[\ln \frac{z_{1}-d}{z_{\mathrm{om}}}-\Psi \mathrm{m}\right]\left[\ln \frac{z_{2}-d}{z_{\mathrm{ov}}}-\Psi_{\mathrm{v}}\right]}{k^{2} U}
$$

where $z_{1}$ is the measurement height $(\mathrm{m})$ for wind speed, $U\left(\mathrm{~m} \mathrm{~s}^{-1}\right), z_{2}$ the measurement height $(\mathrm{m})$ for air temperature, $T_{\mathrm{a}}\left({ }^{\circ} \mathrm{C}\right)$, and vapor pressure, $e_{\mathrm{a}}(\mathrm{kPa})$, and $d$ the zero plane displacement $(\mathrm{m})$ assumed to be $2 \mathrm{~h} / 3$ ( $h$ being the mean canopy height). The momentum roughness length, $z_{\mathrm{om}}(\mathrm{m})$, can be assumed to be $h / 8$, while the water vapor roughness length, $z_{\mathrm{ov}}(\mathrm{m})$, is typically expressed as $z_{\mathrm{ov}}=z_{\mathrm{om}} \exp \left(-k B^{-1}\right)$, where $k B^{-1}$ is a dimensionless number, taken to be 2 for a low-canopy homogeneously vegetated surface [Ryu et al., 2008; Rigden and Salvucci, 2015]. This assumed value of $k B^{-1}$ is also very close to the observational results of the $k B^{-1}$ by using the EC method in an adjacent grassland area of the present study region [Ma et al., 2008]. The von Karman constant is $k$ with a value of 0.4 , while $\Psi_{\mathrm{m}}$ and $\Psi_{\mathrm{v}}$ are the stability correction functions for momentum and humidity, respectively. On a daily basis, it is usually assumed that $\Psi_{m}=\Psi_{v}=0$ due to neutral atmospheric stability [Brutsaert, 1982] conditions for periods of day or longer.

$\mathrm{ET}_{\mathrm{w}}$ is usually calculated by the Priestley-Taylor equation [Priestley and Taylor, 1972], i.e.,

$$
\mathrm{ETw}=\alpha \frac{\Delta}{\Delta+\gamma} \frac{R \mathrm{n}-\mathrm{G}}{\lambda}=\alpha \mathrm{ET}_{\mathrm{rad}}
$$

where $\alpha$ is the dimensionless Priestley-Taylor coefficient. A default value of 1.26 was given by Priestley and Taylor [1972], but recent studies have found the possible regional variations in $\alpha$ value [Ma et al., 2015; Szilagyi, 2007; Szilagyi et al., 2014].

By normalizing equation (1) with $\mathrm{ET}_{\mathrm{p}}$, one obtains

$$
\frac{\mathrm{ET}_{\mathrm{a}}}{\mathrm{ET}_{\mathrm{p}}}=\alpha\left(1+\frac{1}{\eta}\right) \frac{\mathrm{ET}_{\mathrm{rad}}}{\mathrm{ET}_{\mathrm{p}}}-\frac{1}{\eta}
$$

with specified values of $\alpha$ and $\eta,\left(\mathrm{ET}_{\mathrm{a}} / \mathrm{ET}_{\mathrm{p}}\right)$ becomes a linear function of $\left(\mathrm{ET}_{\mathrm{rad}} / \mathrm{ET}_{\mathrm{p}}\right)$ in equation (8). However, Han et al. [2011, 2012] claimed that this linear relationship is only valid in conditions that are neither extremely arid nor extremely wet. In addition, there is still much uncertainty and even controversy about the determination of $\eta$ (i.e., symmetric or asymmetric CR) for different environmental settings [Jaksa et al., 2013; Pettijohn and Salvucci, 2009; Szilagyi, 2007]. Moreover, equation (7) cannot represent the "wet environment" $\mathrm{ET}_{\mathrm{w}}$ very well when the measured actual air temperature is used to calculate $\Delta$ in arid or semiarid environments [Huntington et al., 2011; Ma et al., 2015; Szilagyi, 2014; Szilagyi and Jozsa, 2008; Szilagyi et al., 2009]. In order to broaden the applicability of the $\mathrm{CR}$ approach in estimating $\mathrm{ET}_{\mathrm{a}}$, Han et al. [2012] proposed a nonlinear function between $\left(E T_{a} / E T_{p}\right)$ and $\left(E T_{r a d} / E T_{p}\right)$ as an improvement for equation (8), i.e.,

$$
\frac{\mathrm{ET}_{\mathrm{a}}}{E \mathrm{~T}_{\mathrm{p}}}=\frac{1}{1+d\left(\frac{\mathrm{ET}_{\mathrm{p}}}{\mathrm{ET}_{\mathrm{rad}}}-1\right)^{n}}
$$

in which $d$ and $n$ are the parameters that should be locally calibrated.

\subsubsection{CRAE Model}

The detailed theory and the assumptions involved in the CRAE model were described by Morton [1983] and recently recoded (replacing FORTRAN-77 with FORTRAN-90) by McMahon et al. [2013]. The most prominent advantage of CRAE is that it does not require wind speed as an input. Simply, an "equilibrium temperature," $T_{\mathrm{p}}\left({ }^{\circ} \mathrm{C}\right)$, is defined as the temperature at which Morton's [1983] energy budget and mass transfer methods yield the same result for the potential evapotranspiration rate of a moist surface, i.e.,

$$
\begin{gathered}
\mathrm{ET}_{\mathrm{p}}^{\mathrm{CRAE}}=\frac{1}{\lambda}\left\{\left(R_{\mathrm{n}}-G\right)-\left[\gamma f_{t}+4 \varepsilon \sigma\left(T_{\mathrm{p}}+273.15\right)^{3}\right]\left(T_{\mathrm{p}}-T_{\mathrm{a}}\right)\right\} \\
\mathrm{ET}_{\mathrm{p}}^{\mathrm{CRAE}}=\frac{1}{\lambda}\left[f_{t}\left(e_{\mathrm{p}}-e_{\mathrm{a}}\right)\right]
\end{gathered}
$$


where $f_{\mathrm{t}}$ is the vapor transfer coefficient $\left(\mathrm{W} \mathrm{m}^{-2} \mathrm{kPa}^{-1}\right)$, a function of atmospheric stability. The land surface emissivity is $\varepsilon, \sigma$ the Stefan-Boltzmann constant $\left(5.67 \times 10^{-8} \mathrm{~W} \mathrm{~m}^{-2} \mathrm{~K}^{-4}\right), T_{\mathrm{a}}$ air temperature $\left({ }^{\circ} \mathrm{C}\right), e_{\mathrm{p}}$ the saturation vapor pressure $(\mathrm{kPa})$ at $T_{\mathrm{p}}$, and $e_{\mathrm{a}}$ the measured actual vapor pressure $(\mathrm{kPa})$ at $T_{\mathrm{a}} . T_{\mathrm{p}}$ can be obtained through iterations from equations (10) and (11) (see the detailed procedure in Morton [1983, pp. 64 and 65]).

For the wet environment evapotranspiration rate [Priestley and Taylor, 1972], Morton [1983] also modified equation (7) of Priestley and Taylor [1972] to account for the equilibrium temperature dependence of both the available energy and the slope of the saturation vapor pressure curve, i.e.,

$$
\mathrm{ET}_{\mathrm{w}}^{\mathrm{CRAE}}=\frac{1}{\lambda}\left[b_{1}+b_{2} \frac{\Delta_{\mathrm{p}}}{\Delta_{\mathrm{p}}+\gamma}\left(R_{\mathrm{n}}-G\right)_{\mathrm{p}}\right]
$$

where $\Delta_{\mathrm{p}}\left(\mathrm{kPa}{ }^{\circ} \mathrm{C}^{-1}\right)$ is the slope of the saturation vapor pressure curve at $T_{\mathrm{p}},\left(R_{\mathrm{n}}-G\right)_{\mathrm{p}}$ is the available energy at $T_{\mathrm{p}}\left(\mathrm{W} \mathrm{m}^{-2}\right)$, i.e., $\left(R_{\mathrm{n}}-G\right)_{\mathrm{p}}=\left(R_{\mathrm{n}}-G\right)-4 \varepsilon \sigma\left(T_{\mathrm{p}}+273.15\right)^{3}\left(T_{\mathrm{p}}-T_{\mathrm{a}}\right) . b_{1}$ accounts for possible advection of energy, significant only during seasons of low net radiation, while $b_{2}$ is another parameter that should be calibrated for a specific region using observational data. The default values of $b_{1}$ and $b_{2}$ are given by Morton [1983] as $14 \mathrm{~W} \mathrm{~m}^{-2}$ and 1.2 , respectively.

Unlike the $\mathrm{ET}_{\mathrm{p}}$ (equation (2)) and $\mathrm{ET}_{\mathrm{w}}$ (equation (7)) used by Brutsaert and Stricker [1979], both $\mathrm{ET}_{\mathrm{p}}^{\mathrm{CRAE}}$ and $\mathrm{E}$ $\mathrm{T}_{\mathrm{w}}^{\mathrm{CRAE}}$ of the CRAE model are purposefully defined by Morton [1983] in a way that ensures the CR to be symmetric, as was introduced by Granger [1989] and validated by Szilagyi [2007]. That is, with the ET and $\mathrm{ET}_{\mathrm{w}}^{\mathrm{CRAE}}$ replacing the $\mathrm{ET}_{\mathrm{p}}$ and $\mathrm{ET}_{\mathrm{w}}$ in equation (1), respectively, the value of $\eta$ equals unity. However, this value of unity may be invalid in other CR-based models [e.g., Jaksa et al., 2013; Kahler and Brutsaert, 2006; Pettijohn and Salvucci, 2009; Szilagyi, 2007]. Note that the original time step of the CRAE model was advocated as being at least 5 day to avoid obvious subsurface heat storage change resulting from abrupt changes in weather conditions [Morton, 1983, p. 69]. However, recent research indicate that $\mathrm{ET}_{\mathrm{a}}$ can also be estimated accurately on a daily scale by the CR [e.g., Han et al., 2014a; Jaksa et al., 2013; Kahler and Brutsaert, 2006; Ma et al., 2015]. Considering that the present in situ observation site includes soil heat flux measurement and has a homogeneous fetch, the CRAE model was also applied on a daily basis to make the temporal resolution of the resulting $\mathrm{ET}_{\mathrm{a}}$ estimates as high as possible.

\subsubsection{Penman-Monteith Approach}

By introducing a bulk surface resistance, $r_{\mathrm{s}}\left(\mathrm{s} \mathrm{m}^{-1}\right)$, the effects of plant structure and stomatal regulation of water vapor diffusion from vegetation were accounted for by Monteith [1965] when he modified the original Penman [1948] equation for obtaining the $\mathrm{ET}_{\mathrm{a}}$ from vegetated surfaces. The Penman-Monteith approach thus assumes that the plant canopy can be considered as a "big leaf" from which heat and vapor escape. The water vapor first has to diffuse through the leaves against a surface resistance before diffusing into the atmosphere against an aerodynamic resistance, $r_{\mathrm{a}}$. Specifically, the Penman-Monteith approach defines $\mathrm{ET}_{\mathrm{a}}$ as

$$
\mathrm{ET}_{\mathrm{a}}=\frac{1 \Delta\left(R_{\mathrm{n}}-G\right)+\rho C_{\mathrm{p}} D / r_{\mathrm{a}}}{\lambda} \frac{\left.r_{\mathrm{s}} / r_{\mathrm{a}}\right)}{\Delta+\gamma(1+r}
$$

with variables defined previously, except for $r_{\mathrm{a}}$ (see description below in the Katerji-Perrier model). 2.4.2.1. Katerji-Perrier Model

Katerji and Perrier [1983] proposed a linear relationship between $r_{\mathrm{s}} / r_{\mathrm{a}}$ and $r^{*} / r_{\mathrm{a}}$ such as

$$
\frac{r_{\mathrm{s}}}{r_{\mathrm{a}}}=a \frac{r^{*}}{r_{\mathrm{a}}}+b
$$

where $a$ and $b$ are site-specific empirical coefficients to be calibrated. The $r^{*}\left(\mathrm{~s} \mathrm{~m}^{-1}\right)$ is the so-called "critical" resistance. Normally $r_{\mathrm{s}}<r^{*}$ in which case $\mathrm{ET}_{\mathrm{a}}$ increases with increasing wind speed, but occasionally $r_{\mathrm{s}}>r^{*}$ in which case $\mathrm{ET}_{\mathrm{a}}$ decreases with increasing wind speed [Katerji et al., 2011; Rana and Katerji, 2008], i.e.,

$$
r^{*}=\frac{\Delta+\gamma}{\Delta} \frac{\rho C_{\mathrm{p}} D}{\gamma\left(R_{\mathrm{n}}-G\right)} .
$$


Table 1. The Input Variables and Parameter Values to be Calibrated in the Four Models

\begin{tabular}{lccccc} 
Approaches & Models & Input Variables $^{\mathrm{a}}$ & Parameter Values to be Calibrated & Basic Description & Main Reference \\
\hline $\mathrm{CR}$ & Nonlinear-CR & $\left(R_{\mathrm{n}}-G\right), T_{\mathrm{a}}, e_{\mathrm{a}}, U, h$ & $d, n$ & Free from prejudging the CR pattern & Han et al. [2012] \\
& CRAE & $\left(R_{\mathrm{n}}-G\right), T_{\mathrm{a}}, e_{\mathrm{a}}$ & $b_{1}, b_{2}$ & Predefined symmetric CR & Morton [1983] \\
Penman-Monteith & Katerji-Perrier & $\left(R_{\mathrm{n}}-G\right), T_{\mathrm{a}}, e_{\mathrm{a}}, U, h$ & $a, b$ & Requires site-specific calibration & Katerji and Perrier [1983] \\
& Todorovic & $\left(R_{\mathrm{n}}-G\right), T_{\mathrm{a}}, e_{\mathrm{a}}, U, h$ & $/$ & Calibration free & Todorovic [1999] \\
\hline
\end{tabular}

${ }^{\mathrm{a}}\left(R_{\mathrm{n}}-G\right)$ : available energy; $T_{\mathrm{a}}$ : air temperature; $e_{\mathrm{a}}$ : actual vapor pressure; $U:$ wind speed; $h$ : mean canopy height.

In the traditional formulation of $r_{\mathrm{a}}$ (equation (6)) used by Brutsaert [1982], the water vapor diffusion is considered from a height of " $z_{\mathrm{ov}}+d$. ." Now it is considered from the canopy top (h) [Rana et al., 1997, 2001], and thus, $r_{\mathrm{a}}$ in the Katerji-Perrier model [Perrier, 1975; Rana et al., 2001] is expressed as

$$
r_{\mathrm{a}}=\frac{\left[\ln \frac{z_{1}-d}{z_{\mathrm{om}}}-\Psi_{\mathrm{m}}\right]\left[\ln \frac{z_{2}-d}{h-d}-\Psi_{\mathrm{v}}\right]}{k^{2} U}
$$

where all variables are defined as before.

\subsubsection{Todorovic Model}

Todorovic [1999] developed a mechanistic scheme to parameterize $r_{\mathrm{s}}$ as a function of climatological variables. In this scheme a quadratic equation was developed, i.e.,

$$
A\left(\frac{r_{\mathrm{s}}}{r_{\mathrm{i}}}\right)^{2}+B\left(\frac{r_{\mathrm{s}}}{r_{\mathrm{i}}}\right)+C=0
$$

where

$$
r_{\mathrm{i}}=\frac{\rho C_{\mathrm{p}} D}{\gamma\left(R_{\mathrm{n}}-G\right)}
$$

is the so-called climatological resistance $\left(\mathrm{s} \mathrm{m}^{-1}\right)$ and $A, B$, and $C$ (all expressed in $\mathrm{kPa}$ ) are defined as

$$
\begin{gathered}
A=\frac{\Delta+\gamma\left(r_{\mathrm{i}} / r_{\mathrm{a}}\right)}{\Delta+\gamma}\left(r_{\mathrm{i}} / r_{\mathrm{a}}\right) D \\
B=-\frac{\gamma}{\Delta} \frac{\gamma}{\Delta+\gamma}\left(r_{\mathrm{i}} / r_{\mathrm{a}}\right) D \\
C=-\frac{\gamma}{\Delta} D
\end{gathered}
$$

Equation (17) only has one positive solution for working out the unknown $r_{\mathrm{s}}$. Thus, the $\mathrm{ET}_{\mathrm{a}}$ can be estimated by the Penman-Monteith approach with equation (13). Note that the $r_{a}$ value in Todorovic model is still based on equation (6) [Todorovic, 1999]. The main merit of the Todorovic model is that in contrast to the other three models, it dispenses with local calibration.

\subsection{Model Input and Evaluation Criteria}

Evaluation of model performance is based on data obtained in the summer season (1 July to 30 September) since $\mathrm{ET}_{\mathrm{a}}$ was very low in the remaining months of the year because of generally frozen soil conditions and scanty precipitation. The input variables of each model are summarized in Table 1. In the present study, the in situ measured net radiation, soil heat flux into the ground, air temperature, actual vapor pressure, and wind speed were all aggregated to a daily scale. For wider applications, the canopy height $(h)$ can be inferred from the vegetation type map and/or remote sensing data that are usually publically accessible. Since we have done extensive investigations at the observation site, the measured mean canopy height $(h=0.03 \mathrm{~m})$ throughout the summer was used directly.

We employed two avenues for evaluating the models: in the first, all models were run with the measured daily meteorological variables of 2013 using the default parameter values found in the literature; in the second, the parameter values were calibrated based on measured meteorological variables and $\mathrm{ET}_{\mathrm{a}}$ of 2012 , and subsequently, the models were run again with the measured daily meteorological variables of 2013 for verification purposes and intermodel comparison. 


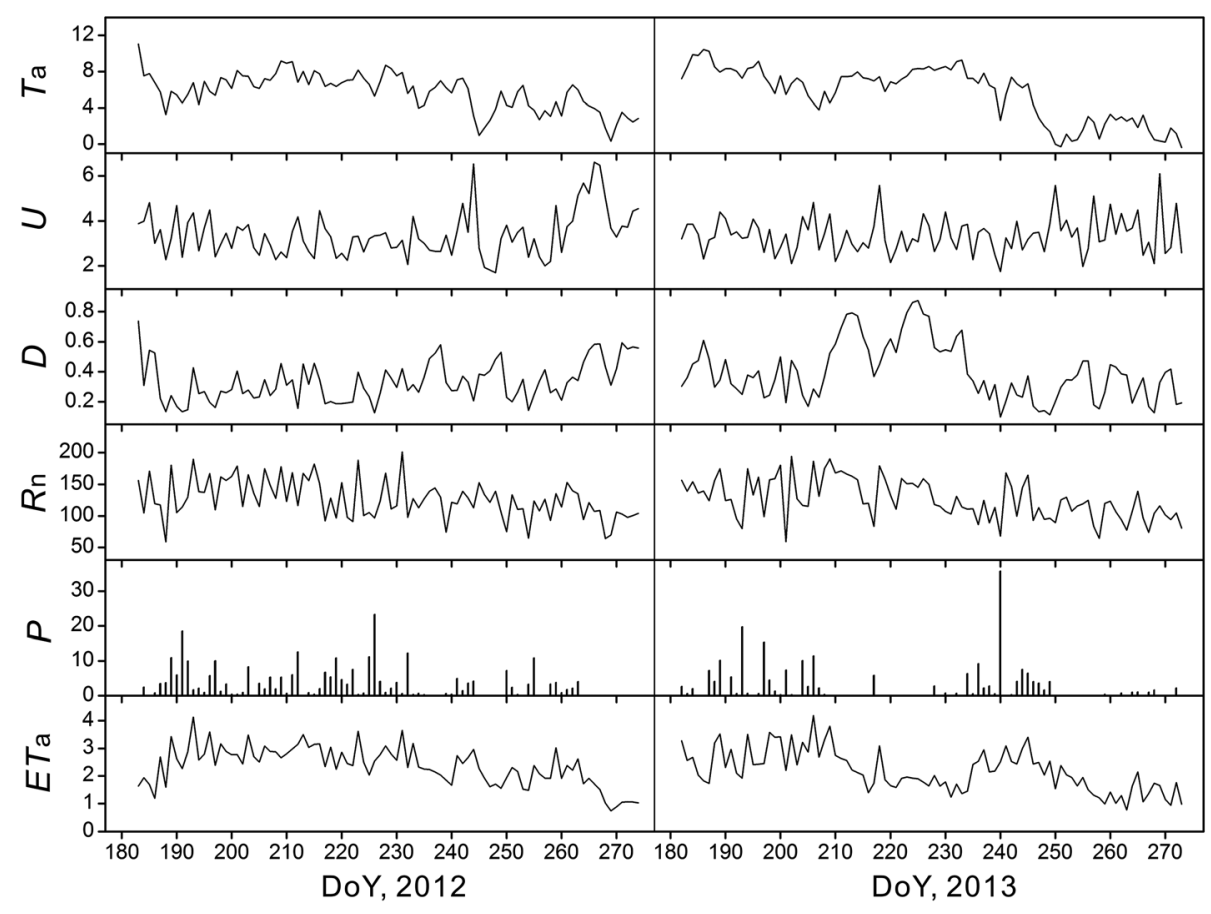

Figure 2. Daily mean air temperature, $T_{\mathrm{a}}\left({ }^{\circ} \mathrm{C}\right)$, wind speed, $U\left(\mathrm{~m} \mathrm{~s}^{-1}\right)$, and vapor pressure deficit, $D(\mathrm{kPa})$, measured at $2 \mathrm{~m}$ above ground as well as daily mean net radiation, $R_{\mathrm{n}}\left(\mathrm{W} \mathrm{m}^{-2}\right)$, daily precipitation, $P\left(\mathrm{~mm} \mathrm{~d}^{-1}\right)$, and BREB-derived actual evapotranspiration, $\mathrm{ET}_{\mathrm{a}}\left(\mathrm{mm} \mathrm{d}^{-1}\right)$ at the observation site from 1 July to 30 September 2012 and 2013. DOY: day of the year.

Model-simulated actual evapotranspiration ( $\mathrm{ET}_{\mathrm{a}-\mathrm{sim}}$ ) rates were evaluated against the measured actual evapotranspiration ( $E T_{a-m e a}$ ) values using the correlation coefficient (CC), mean absolute error (MAE), rootmean-squared error (RMSE), and Nash-Sutcliffe efficiency (NSE):

$$
\begin{gathered}
\mathrm{CC}=\frac{\sum_{i=1}^{j}\left(\mathrm{ET}_{\mathrm{a}-\operatorname{sim}}, i-\overline{\mathrm{ET}_{\mathrm{a}-\text { sim }}}\right)\left(\mathrm{ET}_{\mathrm{a}-\text { mea }}, i-\overline{\mathrm{ET}_{\mathrm{a}-\text {-mea }}}\right)}{\sqrt{\sum_{i=1}^{j}\left(\mathrm{ET}_{\mathrm{a}-\operatorname{sim}}, i-\overline{\mathrm{ET}_{\mathrm{a}-\operatorname{sim}}}\right)^{2} \sum_{i=1}^{j}\left(\mathrm{ET}_{\mathrm{a}-\text { mea }}, i-\overline{\mathrm{ET}_{\mathrm{a}-\text {-mea }}}\right)^{2}}} \\
\mathrm{MAE}=\frac{1}{j} \sum_{i=1}^{j}\left|\mathrm{ET}_{\mathrm{a}-\text {-mea }}, i-\mathrm{ET}_{\mathrm{a}-\text { sim }}, i\right| \\
\mathrm{NSE}=1-\left[\sum_{i=1}^{j}\left(\mathrm{ET}_{\mathrm{a}-\mathrm{mea}}, i-\mathrm{ET}_{\mathrm{a}-\operatorname{sim}}, i\right)^{2}\right] /\left[\sum_{i=1}^{j}\left(\mathrm{ET}_{\mathrm{a}-\text { mea }}, i-\overline{\mathrm{ET}_{\mathrm{a}-\text {-mea }}}\right)^{2}\right]
\end{gathered}
$$

where $\mathrm{ET}_{\mathrm{a}-\mathrm{mea}, i}$ is the $i$ th measured daily actual evapotranspiration value, $\mathrm{ET}_{\mathrm{a}-\mathrm{sim}, i}$ is the $i$ th simulated daily actual evapotranspiration value, $j$ is the total number of the simulated values, and the overbar denotes temporal averaging.

\section{Results and Discussions}

\subsection{Meteorological Background}

Because of the high elevation of the study area, the July-September $2 \mathrm{~m}$ daily mean air temperature stayed at $5.7^{\circ} \mathrm{C}$ and $5.6^{\circ} \mathrm{C}$ in 2012 and 2013 , respectively. The $2 \mathrm{~m}$ daily mean wind speed ranged from 1.7 to $6.6 \mathrm{~m} \mathrm{~s}^{-1}$ and the daily mean vapor pressure deficit ranged from 0.1 to $0.9 \mathrm{kPa}$ (Figure 2). Daily net radiation 


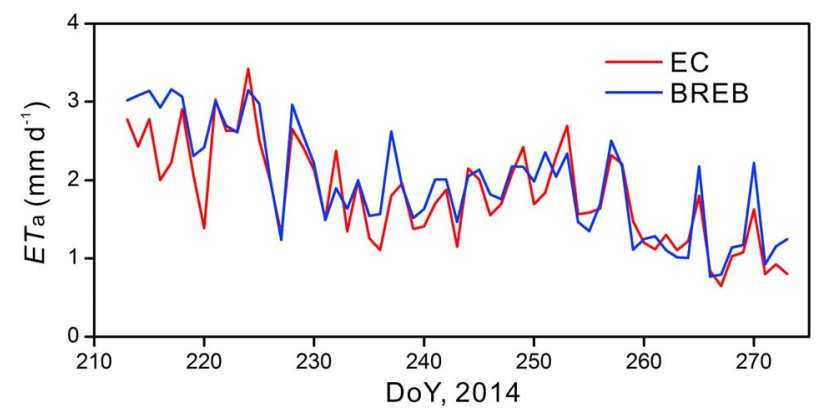

Figure 3. Measured daily $\mathrm{ET}_{\mathrm{a}}$ by the eddy covariance (EC) and Bowen ratio energy balance (BREB) methods, 1 August to 30 September 2014. fluctuated significantly from day to day because of frequent cloudy and rainy weather conditions in the summer. The averages of the daily $R_{\mathrm{n}}$ were $127.0 \mathrm{~W} \mathrm{~m}^{-2}$ and $126.4 \mathrm{~W} \mathrm{~m}^{-2}$ during the study periods of 2012 and 2013, respectively. With regard to rain events, in 2012 they mainly occurred in July and early August, whereas in 2013 they mainly occurred in July, late August, and early September. The daily $\mathrm{ET}_{\mathrm{a}}$, on the whole, showed similar pattern with precipitation. A total of $288.8 \mathrm{~mm}$ of precipitation fell from July to September in 2012 , while only $218.9 \mathrm{~mm}$ was observed during the same period in 2013 . Interestingly, there was no considerable difference in the total $\mathrm{ET}_{\mathrm{a}}$ of these 3 months between the 2 years partly because the precipitation of June 2013 was much larger than that of June 2012 (not shown). The mean daily $\mathrm{ET}_{\mathrm{a}}$ from 1 July to 30 September became $2.4 \mathrm{~mm}$ with a maximum of $4.1 \mathrm{~mm}$ in 2012 and $2.2 \mathrm{~mm}$ with a maximum of $4.2 \mathrm{~mm}$ in 2013 (Figure 2).

\subsection{Comparison of $\mathrm{ET}_{\mathrm{a}}$ by the BREB and EC Methods}

Despite uncertainties about the reliability of the measured air temperature/humidity difference between two measurement heights, the BREB method is regarded as one of the most accurate ways of obtaining $\mathrm{ET}_{\mathrm{a}}$ [Burba, 2013; Wang and Dickinson, 2012] and now is still widely used in a variety of ecosystems with relatively low vegetation [e.g., Billesbach and Arkebauer, 2012; Blanken, 2014; Fischer et al., 2013]. In addition, previous research suggested that $\mathrm{ET}_{\mathrm{a}}$ measured by the BREB method were within $10 \%$ of lysimeter-derived rates in a semiarid lentil field [Prueger et al., 1997] or soil water balance derived rates in a semiarid alfalfa ecosystem [Malek and Bingham, 1993].

Although the present BREB measurement is based on fixed arms, Foken [2008] stated that an increase of the height difference for the sensors enlarges the differences in the temperature/humidity values between the two heights, thereby reducing the systematic error to some extent in the nonexchange BREB method. Considering the quite large homogenous fetch for the present observations, temperature/humidity data measured at 0.7 and $4 \mathrm{~m}$ heights were used for deriving $\mathrm{ET}_{\mathrm{a}}$ by the BREB method in the present study. This height proportion (4/0.7) satisfies the requirement of a 4 to 8 ratio recommended by Foken [2008, p. 126]. Moreover, a recent intercomparison by Savage [2010] also justified that the fixed-arm BREB system with HMP45C sensors is reasonable for measuring the vertical vapor pressure differences to calculate the Bowen ratio. However, to assess the potential uncertainty in the BREB-measured $\mathrm{ET}_{\mathrm{a}}$ values in the present study, they were compared with EC-derived values from 1 August to 30 September 2014 (Figure 3). Overall, the BREB-measured values ( $\mathrm{ET}_{\mathrm{a}-\mathrm{BREB}}$ ) were in good agreement with the $E C$-derived rates $\left(\mathrm{ET}_{\mathrm{a}-\mathrm{EC}}\right)$, resulting in a regression equation of $\mathrm{ET}_{\mathrm{a}-\mathrm{EC}}=0.912 \mathrm{ET}_{\mathrm{a}-\mathrm{BREB}}\left(R^{2}=0.78\right.$, number of samples $\left.=61\right)$. The average

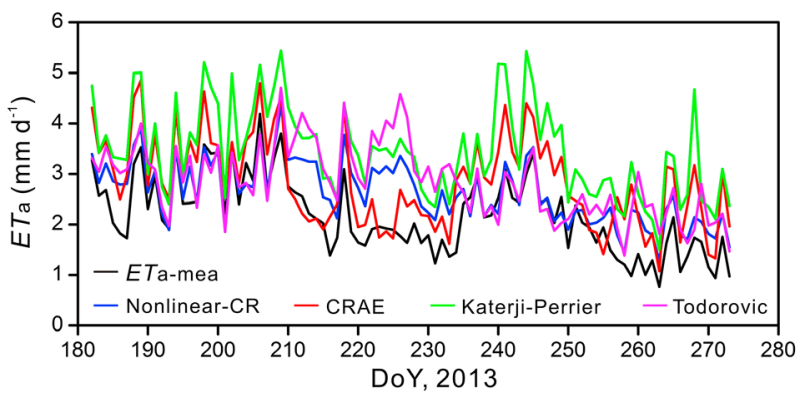

Figure 4. Time series of BREB-measured (ET $\mathrm{a}_{\mathrm{a} \text {-mea }}$ ) and four modelsimulated daily actual evapotranspiration rates using default parameter values, 1 July to 30 September 2013. of the daily absolute percentile difference $\left(\mid E T_{a-B R E B}-E_{a-E C} / E_{a-E C}\right)$ between the two methods is $15.7 \%$. These results are very similar to comparisons between BREB and EC methods at the savannah region of the Sahel [Kabat et al., 1997] and a pasture field of Belgium [Pauwels and Samson, 2006], confirming that the BREB method is reasonable for measuring $\mathrm{ET}_{\mathrm{a}}$ in the present data-scarce region of the TP. Therefore, the BREB-measured $\mathrm{ET}_{\mathrm{a}}$ values were regarded as reliable reference data when model performance is evaluated below. 


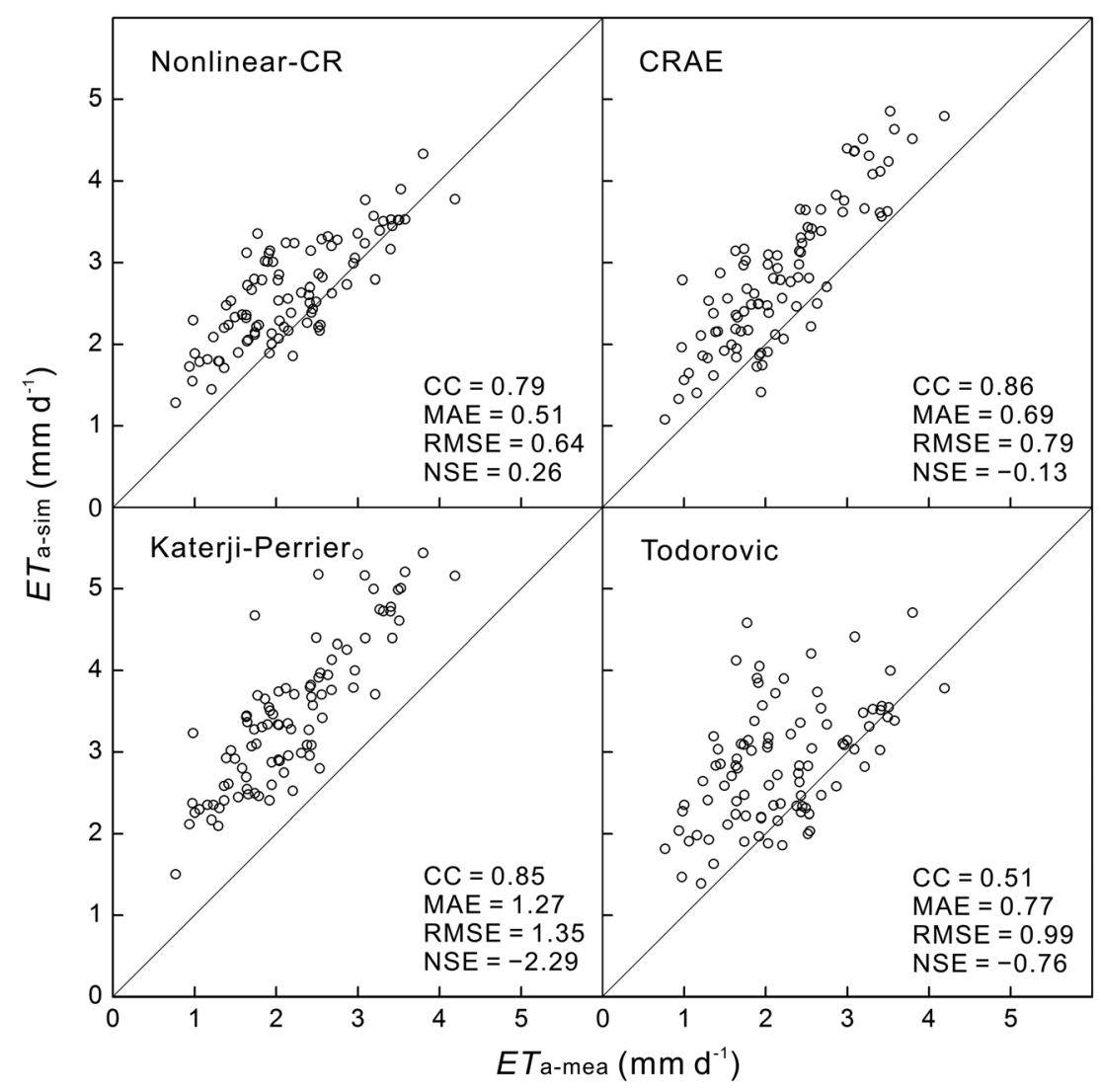

Figure 5. Model-simulated daily actual evapotranspiration ( $\left.\mathrm{ET}_{\mathrm{a}-\mathrm{sim}}\right)$ rates employing default parameter values plotted against BREB-measured daily actual evapotranspiration (ET $\mathrm{T}_{\mathrm{a}-\mathrm{mea}}$ ) rates, 1 July to 30 September 2013.

\subsection{Evaluating Model Performance}

\subsubsection{Model Performance With Default Parameter Values}

Figures 4 and 5 illustrate the performance of the four models for 1 July to 30 September 2013 using default parameter values from Table 2 . Despite high positive correlations between the daily simulated $\left(\mathrm{ET}_{\mathrm{a} \text {-sim }}\right)$ and $\mathrm{BREB}$ measured $\left(\mathrm{ET}_{\mathrm{a}-\mathrm{mea}}\right)$ actual evapotranspiration values, all models generally overshot the measurements resulting in small NSE and large MAE as well as RMSE values (Figure 5). While the Todorovic model performed poorly in most periods when the environment is dry, it displayed very low error during wet conditions (e.g., between day of the year (DOY) 197 and 207 as well as DOY 236 and 249) when intensive rain events occurred (Figure 4). The CRAE and Katerji-Perrier models, however, almost always overestimated $\mathrm{ET}_{\mathrm{a}}$ substantially regardless of weather conditions (Figures 4 and 5). The Nonlinear-CR model has the least bias, reflected in the best NSE value (0.26).

For the 92 day summer season, the Nonlinear-CR and CRAE models overestimated the seasonally cumulative $\mathrm{ET}_{\mathrm{a}}$ by $20.4 \%$ and $29.6 \%$, while the Katerji-Perrier and Todorovic models overestimated it by $57.9 \%$ and $30.7 \%$, respectively.

Table 2. Calibrated Parameter Values and Their Standard Deviations (SD) of the Three Models From Measured Data Between 1 July and 30 September 2012 As Well As the Default Parameter Values From the Literatures ${ }^{a}$

\begin{tabular}{|c|c|c|c|c|c|c|c|}
\hline \multirow[b]{2}{*}{ Models } & \multicolumn{4}{|c|}{ Calibrated } & \multicolumn{3}{|r|}{ Default } \\
\hline & Para1 Values & Para1 SD & Para2 Values & Para2 SD & Para1 Values & Para2 Values & Regions, Reference \\
\hline Nonlinear-CR & 2.544 & 0.305 & 1.531 & 0.104 & 1.41 & 1.39 & $\begin{array}{l}\text { Semiarid Leymus chinensis steppe in northeastern China, } \\
\text { Han et al. [2012] }\end{array}$ \\
\hline CRAE & 0 & 0 & 1.241 & 0.02 & 14 & 1.20 & Arid regions in America, Sudan, and Nigeria, Morton [1983] \\
\hline Katerji-Perrier & 2.237 & 0.123 & -0.955 & 0.227 & 1.497 & -1.718 & Semiarid maize in southeastern Australia, Liu et al. [2012] \\
\hline
\end{tabular}

${ }^{\mathrm{a}}$ Para1 and Para2 denote $d$ and $n$ in the Nonlinear-CR model, $b_{1}$ and $b_{2}$ in the CRAE model, and $a$ and $b$ in the Katerji-Perrier model, respectively. 


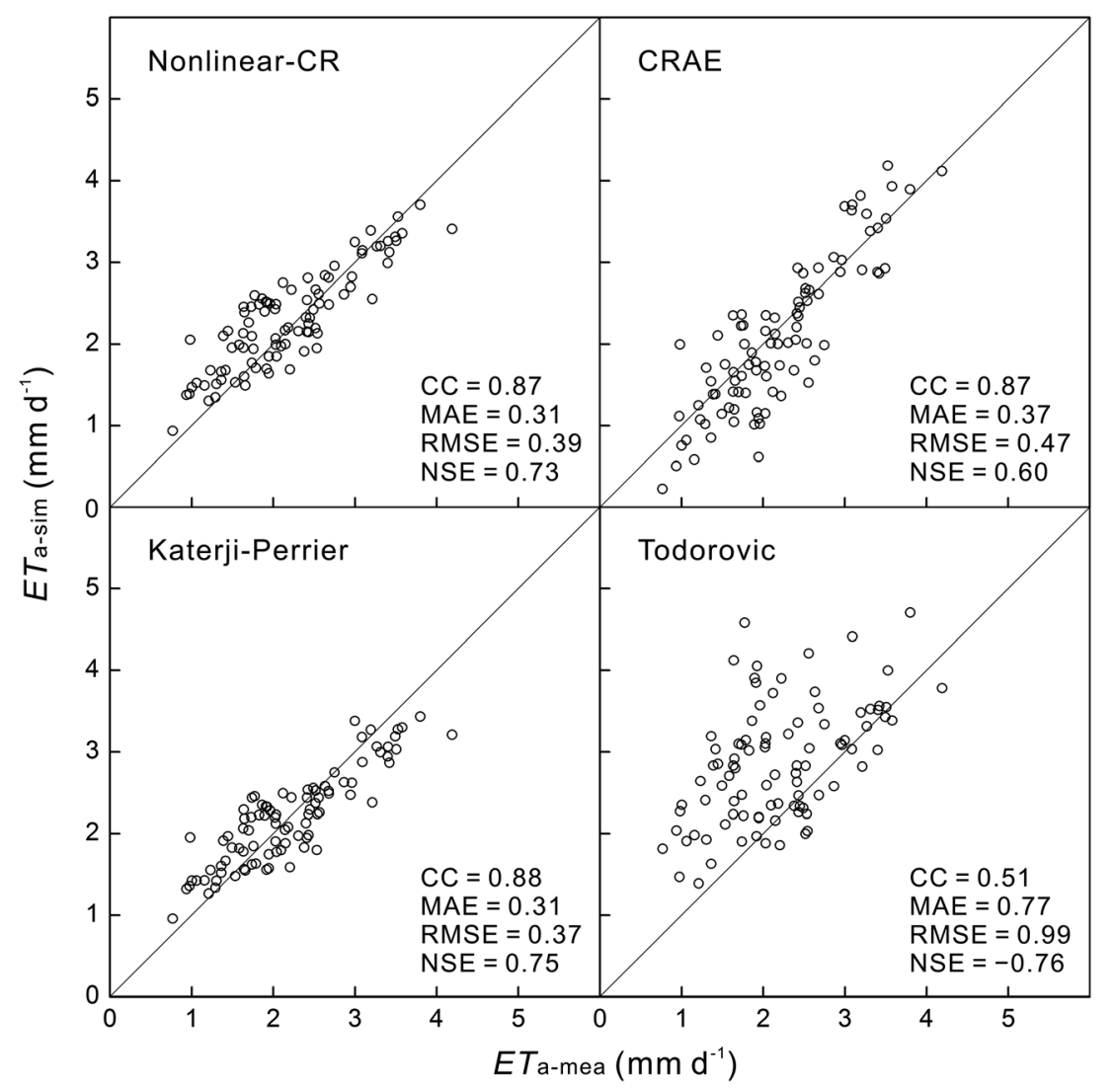

Figure 6. Model-simulated daily actual evapotranspiration ( $\left.\mathrm{ET}_{\mathrm{a}-\mathrm{sim}}\right)$ rates employing calibrated parameter values plotted against BREB-measured daily actual evapotranspiration ( $\mathrm{ET}_{\mathrm{a}-\mathrm{mea}}$ ) rates, 1 July to September 2013.

\subsubsection{Calibration of Model Parameter Values}

The parameter values of the Nonlinear-CR, CRAE, and Katerji-Perrier models were calibrated with the measured meteorological variables and BREB-derived $\mathrm{ET}_{\mathrm{a}}$ from 1 July to 30 September 2012 (Table 2). Note that the Todorovic model does not have any parameters to calibrate. For the Nonlinear-CR model, Han et al. [2012]

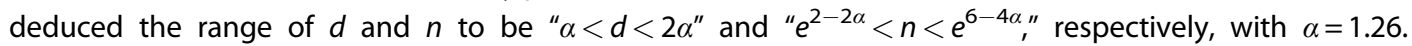
Considering the $\alpha$ values may vary between 1 and 1.6 in different regions [Szilagyi, 2007; Szilagyi et al., 2014], the calibrated $d$ (2.544) and $n$ (1.531) values are close to the ranges above defined by Han et al. [2012]. Since the measurement location is homogeneous enough in terms of its fetch for the fluxes and the study period is summer, $b_{1}$ in the CRAE model could be set to zero. Interestingly, the optimized $b_{2}$ (1.241) is still close to the initial value of Morton [1983]. Katerji and Rana [2006] stated that the $a$ and $b$ values of the Katerji-Perrier model may vary substantially by regions. Therefore, obvious differences in parameter values appear in the Katerji-Perrier model due to significant differences in climatic and surface conditions when compared to previous studies.

\subsubsection{Model Performance With Calibrated Parameter Values}

Since the Todorovic model has no parameter to calibrate, its performance could not be improved. The negative NSE (Figure 5) suggests that it should not be used to estimate $\mathrm{ET}_{\mathrm{a}}$ in the semiarid region of the TP except for days when significant precipitation occurs. However, the other three models, with their locally calibrated parameter values, generally captured the variation in $\mathrm{ET}_{\mathrm{a}}$ well (Figure 6). The NSE of the Nonlinear-CR and Katerji-Perrier models became as high as 0.73 and 0.75 , respectively (Figure 6), suggesting that they are appropriate for the estimation of $\mathrm{ET}_{\mathrm{a}}$ in the data-scarce region of the TP. The MAE indicator of the Nonlinear-CR and Katerji-Perrier (both are $0.31 \mathrm{~mm}$ ) models is less than half of the standard deviation of measured $\mathrm{ET}_{\mathrm{a}}$ (the average of daily $\mathrm{ET}_{\mathrm{a}}$ values for the validation period is $2.2 \mathrm{~mm}$, with a standard deviation of $0.7 \mathrm{~mm}$ ), indicating very good performance. The RMSE of these two models exceeded MAE by only $25.8 \%$ and $19.4 \%$ (Figure 6), respectively, demonstrating general absence of outliers in the $\mathrm{ET}_{\mathrm{a}}$ estimates [Legates and McCabe, 1999]. 


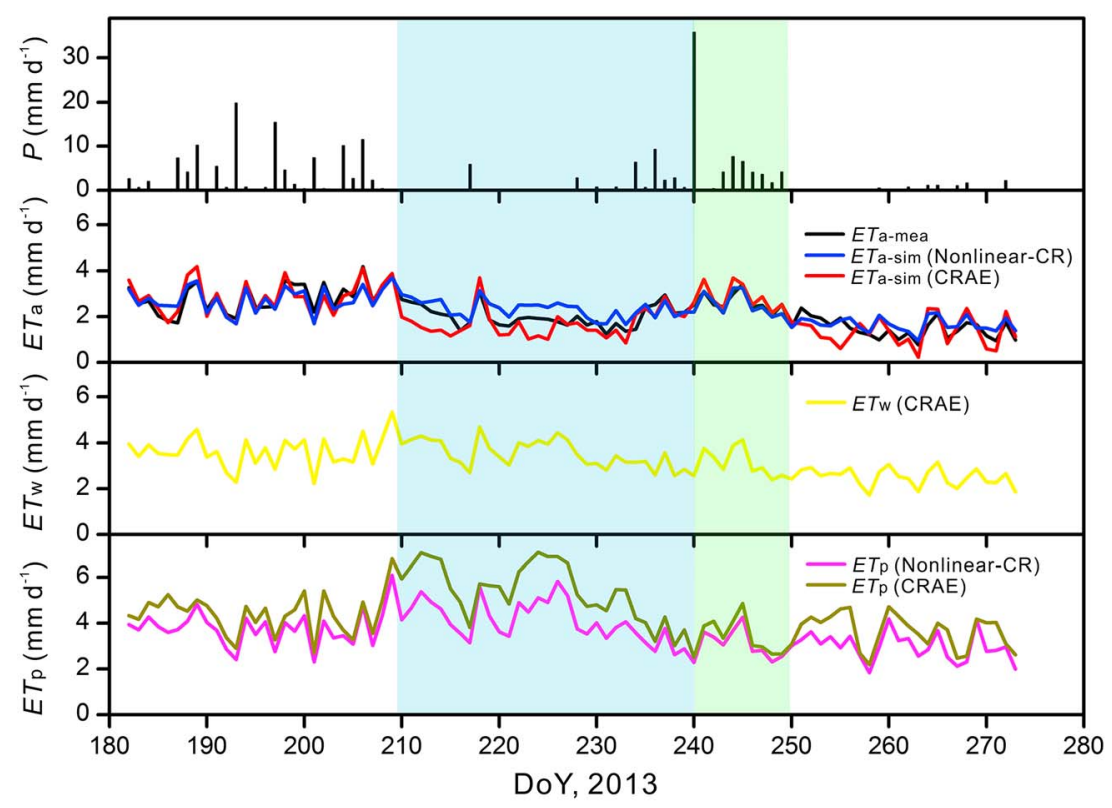

Figure 7. Daily precipitation (P), BREB-measured actual evapotranspiration (ET $\mathrm{a}_{\mathrm{a}-\mathrm{mea}}$ ), and $\mathrm{CR}$-based models simulated actual $\left(E T_{a-s i m}\right)$, wet environment $\left(E T_{w}\right)$, and potential $\left(E T_{p}\right)$ evapotranspiration rates with the calibrated parameter values from 1 July to 30 September 2013. The light blue/green shades denote periods when actual and potential evapotranspiration rates displayed negative/positive correlations.

The NSE value of the CRAE model (0.60) is only a bit lower than that of the Nonlinear-CR model, and its MAE and the RMSE values are also acceptable (Figure 6), thereby signifying an overall good performance. Considering that no information of wind speed and ground surface condition (e.g., canopy height) is required by the CRAE model (in contrast to the Nonlinear-CR and Katerji-Perrier models), it is well suited for large-scale applications with long data sets, especially where data for calculating $r_{\mathrm{a}}$ and $r_{\mathrm{s}}$ are missing.

The reasonable performances of these three calibrated models at a daily scale also made for accurate estimates at the seasonal scale. For the 92 day summer season of 2013, the relative error of the cumulative $\mathrm{ET}_{\mathrm{a} \text {-sim }}$ from Nonlinear-CR, CRAE, and Katerji-Perrier models were $5.4 \%,-5.1 \%$, and $-0.1 \%$ when compared with the cumulative $\mathrm{ET}_{\mathrm{a}-\mathrm{mea}}$, respectively.

\subsection{Possible Causes for Differences in Model Performance}

\subsubsection{CR Approach}

With the help of CR theory employing net radiation, air temperature and pan evaporation (the latter as a proxy of potential evapotranspiration), Brutsaert [2013] concluded that terrestrial $\mathrm{ET}_{\mathrm{a}}$ in the TP has increased at a rate of $0.69 \mathrm{~mm}$ per year from 1966 to 2000, prompting for modeling long-term $\mathrm{ET}_{\mathrm{a}}$ over the TP, where the harsh climate has led to extremely sparse in situ observations. However, general applications of CR-based models in arid and semiarid environments need further evaluations. Hobbins et al. [2001a, 2001b] found that increasing aridity resulted in increased absolute error of the AA model with its original parameter values, while great improvements could be achieved when the wind function and the Priestley-Taylor coefficient, $\alpha$, were locally recalibrated. In addition, after comparing three different CR-based models in different regions, $X u$ and Singh [2005] demonstrated that the original parameter values of CR-based models would lead to large errors in arid regions and conversely to small errors in humid ones. Similar comparison in the Yellow River basin of China by Liu et al. [2006] also suggested that the CR-based models with default parameter values tended to significantly overestimate $\mathrm{ET}_{\mathrm{a}}$ in dry years but performed better in humid years. In the present semiarid region of the TP, the accuracy of the Nonlinear-CR and CRAE models were substantially improved with locally calibrated parameter values.

According to Huntington et al. [2011], the success of the CR-based models depends on whether $\mathrm{ET}_{\mathrm{a}}$ is sensitive to fast changes in surface moisture conditions. In arid and semiarid regions without the influence of groundwater, surface moisture is mainly determined by precipitation. In the present study, both the measured and simulated $\mathrm{ET}_{\mathrm{a}}$ patterns overall follow that of rain (Figure 7). Taking DOY 209 to 227 as an example, there was only one rain 
event with $5.9 \mathrm{~mm}$ of precipitation (this occurred on DOY 217) during the 19 day period; hence, measured and simulated $\mathrm{ET}_{\mathrm{a}}$ values overall decreased (except the sharp jump immediately after DOY 217), while both $\mathrm{ET}_{\mathrm{p}}$ values increased gradually (except some days with lower available energy illustrated by low $\mathrm{ET}_{\mathrm{w}}$ ). During a series of small rain events from DOY 228 to 238, another inverse relationship could also be seen between $\mathrm{ET}_{\mathrm{a}}$ and $\mathrm{ET}_{\mathrm{p}}$, where the former increased while the latter decreased. Interestingly, a positive correlation between $\mathrm{ET}_{\mathrm{a}}$ and $\mathrm{ET}_{\mathrm{p}}$ occurred from DOY 240 to 249: $\mathrm{ET}_{\mathrm{a}}$ first increased from DOY 240 to 244 due to plenty of water supply from rain; but $\mathrm{ET}_{\mathrm{a}}$ then decreased from DOY 245 to 249 as a response to an obvious decrease in available energy resulting in decreased $\mathrm{ET}_{\mathrm{p}}$, although additional rain events occurred during this 5 day period (Figure 7).

As CRAE does not require wind speed data, it has been applied extensively in areas where long-term wind records are absent [Chiew and Leahy, 2003; Leydecker and Melack, 2000; Szilagyi and Jozsa, 2008]. While Morton [1983] did not recommend application of the CR-based models for periods shorter than 5 days, Jaksa et al. [2013] and Huntington et al. [2011] have demonstrated the high efficiency of a modified AA model in simulating daily $\mathrm{ET}_{\mathrm{a}}$ within the semiarid grasslands of Idaho and the arid shrublands of Nevada, respectively. In the present study, both the Nonlinear-CR and CRAE models yielded good agreement with measured $\mathrm{ET}_{\mathrm{a}}$ on a daily basis within a semiarid alpine steppe setting of the TP. Although the two models behaved quite similarly, the CRAE model expressed a bit larger bias for a few short periods (e.g., DOY 210-215 in Figure 7). A likely explanation is that CRAE assumes that the wind speed has no effect on the vapor transfer coefficient, an assumption that may not be valid consistently in practical applications [Granger and Gray, 1990] resulting in biased $\mathrm{ET}_{\mathrm{p}}$ estimates, thereby leading to some deviations in $\mathrm{ET}_{\mathrm{a}-\mathrm{sim}}$.

\subsubsection{Penman-Monteith Approach}

The early applications of the Penman-Monteith-based models usually assume $r_{\mathrm{s}}$ as a fixed (or prescribed) constant to obtain the potential evapotranspiration rate, and subsequently a correction factor is introduced to calculate actual evapotranspiration. Such an avenue of thinking is called "two-step method" [Shuttleworth, 2007], and one of its widely used examples is the well-known Food and Agriculture Organization crop coefficient method [Allen et al., 1998], which combines reference evapotranspiration and a crop coefficient to deduce the $\mathrm{ET}_{\mathrm{a}}$ of a given ecosystem [e.g., Yang and Zhou, 2011]. It should be noted that any correction factors in the two-step method actually have little physical meanings related to the land evapotranspiration process [Shuttleworth, 2007]. The $r_{\mathrm{s}}$ in fact, could vary markedly in vegetated areas due to environmental and biological controls, e.g., variations in soil moisture or atmospheric humidity deficit [Baldocchi et al., 1997, 2004; Brümmer et al., 2012; Wever et al., 2002] as well as changes in leaf area index of vegetation [Saigusa et al., 1998; Wilson and Baldocchi, 2000; Zenone et al., 2015]. Many of these stress factors have also been explicitly incorporated into the second-generation LSMs to improve $\mathrm{ET}_{\mathrm{a}}$ simulations in large-scale land-atmosphere interaction studies [Sellers et al., 1997; Shuttleworth, 2007]. That is, the accuracy of the simulated time variant bulk surface resistance plays a critical role in determining the effectiveness of the Penman-Monteith-based models. The early theoretical analysis of McNaughton and Spriggs [1986] suggested that the $r_{\mathrm{s}}$ would significantly influence $\mathrm{ET}_{\mathrm{a}}$ as long as its value is in excess of $62.5 \mathrm{~s} \mathrm{~m}^{-1}$. By exploring the sensitivity of $r_{\mathrm{s}}$ in the Penman-Monteith approach for grassland with a canopy height of approximately $0.1 \mathrm{~m}$, Katerji and Rana [2006] reported that the variation of $r_{\mathrm{s}}$ could explain 20\% (well-watered conditions) to 70\% (water-stressed conditions) of the $\mathrm{ET}_{\mathrm{a}}$ variation. Therefore, the present one-step Penman-Monteith approach with suitable $r_{\mathrm{s}}$ should be taken as a priority for estimating $\mathrm{ET}_{\mathrm{a}}$.

The Todorovic model assumes that heat transfer resistance is equal to $r_{\mathrm{s}}$ [Todorovic, 1999]. This is to a large extent unrealistic because the former is principally determined by wind speed [Yang et al., 2008], whereas $r_{\mathrm{s}}$ is under the influence of, as mentioned above, numerous environmental and biological controls. Moreover, the Todorovic model was proposed using observational data in a grassland under optimal soil moisture conditions [Todorovic, 1999], assuming that $r_{\mathrm{s}}$ hinges only on meteorological conditions, thus excluding the effect of soil moisture availability on $r_{s}$. This not only explains why Lecina et al. [2003] could successfully apply the Todorovic model in regularly irrigated grasslands, but it also explains why the results of the Todorovic model in the present study, to some extent, agreed well with $\mathrm{ET}_{\mathrm{a}-\mathrm{mea}}$ during rainy days (Figure 8). However, it is not uncommon to encounter water-stressed conditions in arid and semiarid environments, to which $r_{\mathrm{s}}$ is sensitive. Figure 8 clearly illustrates that the $r_{\mathrm{s}}$ values were significantly underestimated by the Todorovic model during the days when no rain events occurred, thereby markedly overestimating $\mathrm{ET}_{\mathrm{a}}$. The poor performance of the Todorovic model in the present alpine steppe environment is in accordance with previous findings over a temperate mixed forest in northeastern China [Shi et al., 2008] and over a series of crops in southern Italy [Katerji et al., 2011]. 


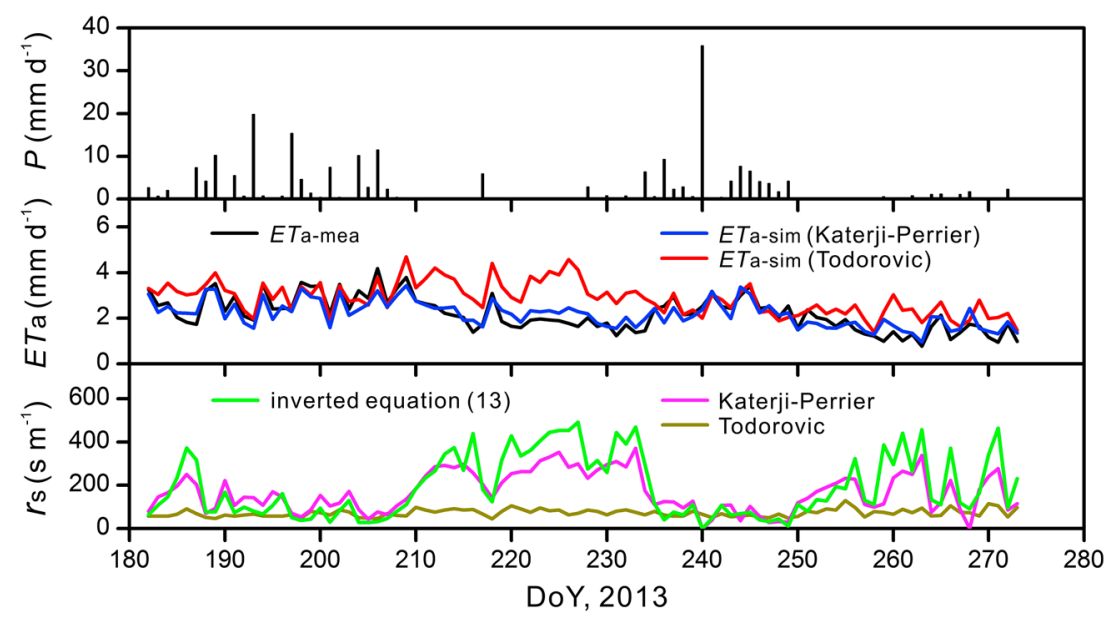

Figure 8. Daily precipitation ( $P$ ), BREB-measured ( $\mathrm{ET}_{\mathrm{a}-\mathrm{mea}}$ ), and Penman-Monteith-based models simulated (ET $\mathrm{a-sim}$ ) actual evapotranspiration with the calibrated parameter values from 1 July to 30 September 2013. The bulk surface resistance $\left(r_{\mathrm{s}}\right)$ is derived (i) from inverting the Penman-Monteith equation (13) with the BREB-measured $\mathrm{ET}_{\mathrm{a}}$ values, (ii) from the KaterjiPerrier model, and (iii) from the Todorovic model.

In contrast, the parameters $a$ and $b$ in the Katerji-Perrier model are site dependent and incorporate the effect of soil water status on $r_{\mathrm{s}}$ [Katerji et al., 2011; Rana et al., 2001]. This model can therefore be used in wider environmental settings. The $r_{\mathrm{s}}$ values derived from the Katerji-Perrier model were comparable to the $r_{\mathrm{s}}$ values derived by inverting the Penman-Monteith approach (equation (13)) with the BREB-measured ET $\mathrm{a}_{\mathrm{a}}$ (Figure 8). Since the $a$ and $b$ values are specific of land cover type, local calibration of their values with the help of measured $\mathrm{ET}_{\mathrm{a}}$ is therefore necessary before one can apply the model to estimate actual evapotranspiration for a given area.

\subsection{Sensitivity Analysis of Model Parameter Values}

In order to assess how sensitive the models are to their calibrated parameter values, a sensitivity analysis similar to Timmermans et al. [2007] and Long et al. [2011] was performed. Specifically, by changing each parameter value from its calibrated one at a $\pm 10 \%$ perturbation within the $\pm 50 \%$ range, variations in the resulting $\mathrm{ET}_{\mathrm{a}-\mathrm{sim}}$ values are calculated as

$$
\left(\frac{H_{ \pm}-H_{\mathrm{o}}}{H_{\mathrm{o}}}\right) \times 100 \%
$$

where $H_{\mathrm{o}}$ is the $\mathrm{ET}_{\mathrm{a} \text {-sim }}$ using the locally calibrated parameter values in Table 2 , and $H_{ \pm}$is the $\mathrm{ET}_{\mathrm{a} \text {-sim }}$ using the perturbed parameter values without varying other parameters. Note that systematically decreasing the value of $b_{2}$ may lead to negative actual evapotranspiration estimates in the CRAE model, as indicated in the equation (1). Therefore, whenever the CRAE-simulated $\mathrm{ET}_{\mathrm{a} \text {-sim }}$ values became negative, they were replaced by zero during the sensitivity analysis. Note also that the percentile variation was not applied to $b_{1}$ in the CRAE model since its reference value is 0 (Table 2). Instead, we set $b_{1}$ to either 7 or $14 \mathrm{~W} \mathrm{~m}^{-2}$ because the original value of $b_{1}$ was $14 \mathrm{~W} \mathrm{~m}^{-2}$ in the CRAE model [Morton, 1983, p. 25].

Figure 9 displays the maximum, minimum, and mean of the $\mathrm{ET}_{\mathrm{a}-\mathrm{sim}}$ values produced by each perturbation of the parameter values in the corresponding model. Generally, there were no obvious sensitivity differences between $d$ and $n$ in the Nonlinear-CR model, except for their opposite effects. For example, a 10\% increase in $d$ leads to a $-3.3 \%$ decrease in $\mathrm{ET}_{\mathrm{a}-\text { sim }}$, while the same proportional change of $n$ would result in a $4.6 \%$ increase of $\mathrm{ET}_{\mathrm{a} \text {-sim. }}$. With regard to the Katerji-Perrier model, it seems that parameter $b$ does not have large influence on the $\mathrm{ET}_{\mathrm{a} \text {-sim }}$ because a variation of even $50 \%$ only causes a $\sim 10 \%$ change in $\mathrm{ET}_{\mathrm{a} \text {-sim. }}$. However, the model is more sensitive to its parameter $a$. A $-50 \%$ decrease in a could cause a nearly $50 \%$ increase in $\mathrm{ET}_{\mathrm{a}-\mathrm{sim}}$. In terms of the CRAE model, a value of $14 \mathrm{~W} \mathrm{~m}^{-2}$ for $b_{1}$ caused the $\mathrm{ET}_{\mathrm{a}-\mathrm{sim}}$ to increase $61.7 \%$. In other words, if the default value $\left(14 \mathrm{~W} \mathrm{~m}^{-2}\right)$ of $b_{1}$, recommended by Morton [1983], is employed without calibration, the CRAE model is likely to produce more than $60 \%$ overestimation of the actual evapotranspiration rate 


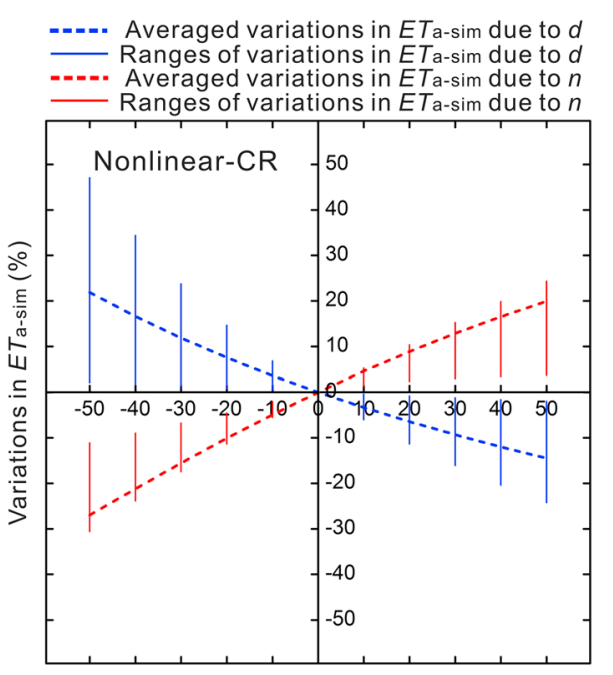

Variations in parameter values (\%)

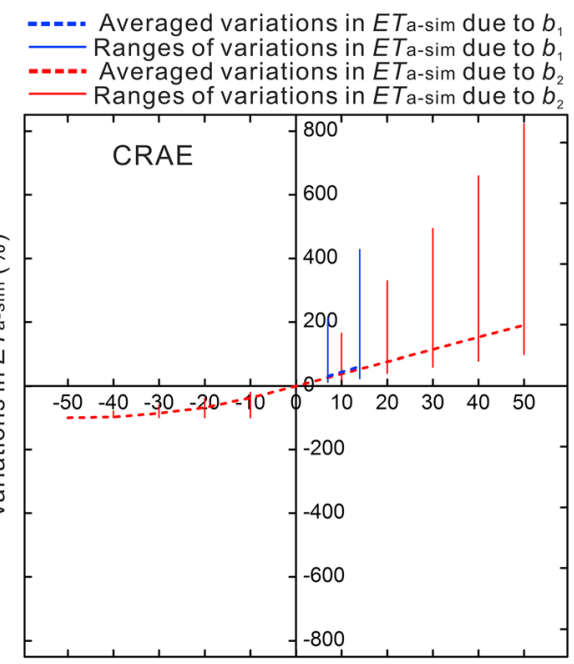

Variations in parameter values ( $\%$ is only for $\left.b_{2}\right)$

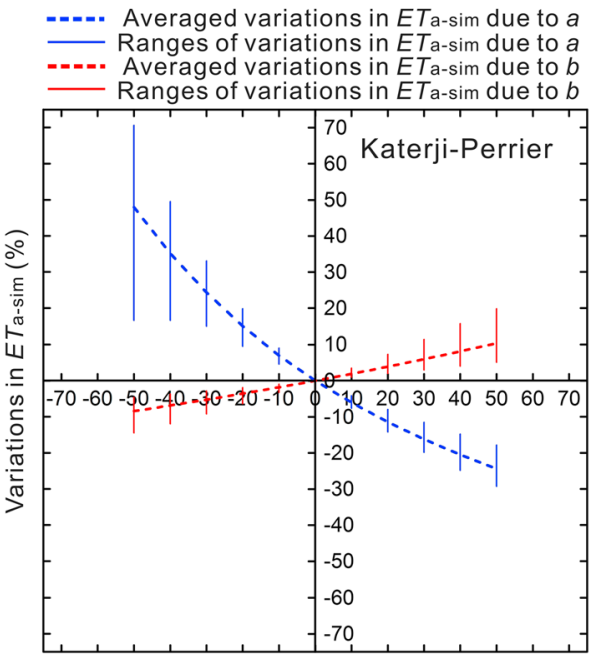

Variations in parameter values (\%) in the present study region. Also, a $10 \%$ increase in $b_{2}$ can lead to a $38 \%$ corresponding increase in $\mathrm{ET}_{\mathrm{a}-\mathrm{sim}}$, indicating that the CRAE model is sensitive to its parameters.

On the whole, the Nonlinear-CR model is the least sensitive to its own parameters (Figure 9). In the light of it, when measured $\mathrm{ET}_{\mathrm{a}}$ data are lacking for site-specific calibration, one may be advised to give preference to the NonlinearCR model with literature-derived parameter values calibrated under similar climatic and land cover conditions.

\subsection{Outlook for Deriving Long-Term ET ${ }_{a}$ in TP Using CR and Penman-Monteith Approaches}

With significant declines in solar radiation and wind speed as well as an obvious increase in temperature over the past four decades [Yang et al., 2011; Yin et al., 2013a], the overall increase of precipitation [Li et al., 2014; Gao et al., 2015; Yang et al., 2011; Zhong et al., 2011] has resulted in increased $\mathrm{ET}_{\mathrm{a}}$ in most nonhumid regions of TP [e.g., $\mathrm{Li}$ et al., 2014; Yin et al., 2013a, 2013b; Yang et al., 2011; Zhang et al., 2007]. Perhaps the most traditional approach of deriving long-term $\mathrm{ET}_{\mathrm{a}}$ is the water balance method (i.e., the deficit between precipitation and runoff while accounting for changes in soil water and groundwater content). For example, with the help of precipitation and runoff data in 16 catchments of TP, Zhang et al. [2007] found that annual $\mathrm{ET}_{\mathrm{a}}$ displayed an increasing trend (not significant) with a rate of $0.7 \mathrm{~mm} \mathrm{yr}^{-1}$ from 1966 to 2001 . However, using the LSM-based and reanalysis-based $\mathrm{ET}_{\mathrm{a}}$ products, Li et al. [2014] reported that the annual $\mathrm{ET}_{\mathrm{a}}$ over upper Yangtze River, upper Yellow river, and Qiangtang basins in TP have increased during 1983-2006 with rates of $0.7,0.8$, and $1.8 \mathrm{~mm} \mathrm{yr}^{-1}$, respectively. Furthermore, the investigation of Yin et al. [2013a, 2013b] who implemented the Lund-Potsdam-Jena dynamic vegetation model suggested that the plateau-averaged annual $\mathrm{ET}_{\mathrm{a}}$ accelerated significantly with $1.5 \mathrm{~mm} \mathrm{yr}^{-1}$ during 1981-2010. Although it is not appropriate to compare the sensitivities of $\mathrm{ET}_{\mathrm{a}}$ to climate change with different methods when the research periods are not consistent, one should realize that different methods rely on different assumptions and inputs. In other words, whether the methods' applicability and their data input are adequate in the TP or not determines to large extent the reliability of the simulated $\mathrm{ET}_{\mathrm{a}}$ and its sensitivity to climate change. For example, difficulties in the estimation of glacier meltwater can make the traditional water balance method laden with high uncertainty

Figure 9. The maximum, minimum, and mean change in the simulated actual evapotranspiration ( $\mathrm{ET}_{\mathrm{a}-\mathrm{sim}}$ ) values with perturbations (within the range of $\pm 10 \%$ to $\pm 50 \%$ ) of $d$ and $n$ for the Nonlinear-CR, $b_{2}$ for CRAE, and $a$ and $b$ for the Katerji-Perrier model around their calibrated values. The $b_{1}$ of CRAE was only assigned to two values, 7 and $14 \mathrm{~W} \mathrm{~m}^{-2}$, respectively. 
(i.e., underestimating $\mathrm{ET}_{\mathrm{a}}$ ) in cold regions like the TP. This is especially true with consideration that global warming has caused substantial glacier retreat in the past few decades across the TP [Yao et al., 2007, 2012]. It should also be noted that the majority of the available researches on long-term $\mathrm{ET}_{\mathrm{a}}$ variability of the TP were based on relatively coarse (e.g., annual or monthly) temporal resolutions (due to paucity of, e.g., high-resolution soil moisture data). In water-limited environment, however, $\mathrm{ET}_{\mathrm{a}}$ would respond most strongly to changes in rainfall [Kurc and Small, 2004; Ma et al., 2014; Wever et al., 2002]. The precipitation in the alpine grassland of the TP is subject not only to the dynamics of the Southern Asian monsoon but also to local moisture recycling [Yao et al., 2013; Tian et al., 2001]. Therefore, it is believed that simulating $\mathrm{ET}_{\mathrm{a}}$ on finer temporal resolutions (e.g., daily) could be more helpful to understanding the hydrological processes and their response to climate change in TP. This way the CR and Penman-Monteith approaches particularly would benefit future long-term $\mathrm{ET}_{\mathrm{a}}$ reconstruction over the TP because of their merits (e.g., requirement for inputs and temporal resolution) that are illustrated in the present study.

\section{Conclusions}

Deriving actual evapotranspiration rates, $\mathrm{ET}_{\mathrm{a}}$, from routinely obtained meteorological variables is critical for regions where in situ flux observations are sparse. Based on comparisons of the effectiveness and parameter sensitivity of the four models, the implications for estimating daily $\mathrm{ET}_{\mathrm{a}}$ in the data-scarce region of the TP are as follows: (i) The Katerji-Perrier model is preferable when measured $\mathrm{ET}_{\mathrm{a}}$ data are available to calibrate the parameter values. (ii) In the absence of measured $\mathrm{ET}_{\mathrm{a}}$ data, the Nonlinear-CR model is preferable because of its stable parameter values making it possible to employ published parameter values derived under similar climatic and land cover conditions. (iii) In regions with no information of wind speed and ground surface conditions (e.g., canopy height), the $\mathrm{ET}_{\mathrm{a}}$ may still be obtained by the CRAE model. In homogeneous areas $b_{1}$ may be set equal to zero (as was done here), but for heterogeneous surfaces some measured $\mathrm{ET}_{\mathrm{a}}$ data may be necessary to aid the proper choice for its value. (iv) The Todorovic model is not recommended in arid and semiarid regions of the TP because of its significant underestimation of the bulk surface resistance under water-stressed conditions. Although the harsh environment has led to rather sparse in situ $\mathrm{ET}_{\mathrm{a}}$ observations in the TP, the present findings can help in choosing a suitable model to gain information on long-term $\mathrm{ET}_{\mathrm{a}}$ across the TP involving spatial interpolation of routine meteorological observations and possible remote sensing data.

Acknowledgments

This research was supported by the Strategic Priority Research Program (B) of CAS (XDB03030200) and the National Natural Science Foundation of China (41190080 and 41430748). The members of Zhang's group did a hardwork in the field for the in situ observation. We would like to express sincere gratitude to Songjun Han for a wide range of helpful discussions on the CR theory and constructive comments on this paper. We also thank Yuanhe Yang for sharing the materials in Figure 1 and Xiuping Li for sharing the original data in her publication. We are grateful to the Associate Editor and three anonymous reviewers for their comments that greatly improved the earlier manuscript. The data used for the figures and tables may be available upon request from the corresponding author.

\section{References}

Allen, R. G., L. S. Pereira, D. Raes, and M. Smith (1998), Crop Evapotranspiration: Guidelines for Computing Crop Water Requirements, Irrig. and Drain. Pap. 56, United Nations FAO, Rome.

Allen, R. G., L. S. Pereira, T. A. Howell, and M. E. Jensen (2011), Evapotranspiration information reporting: I. Factors governing measurement accuracy, Agric. Water Manage., 98(6), 899-920.

Baldocchi, D. D. (2014), Measuring fluxes of trace gases and energy between ecosystems and the atmosphere-the state and future of the eddy covariance method, Global Change Biol., 20(12), 3600-3609.

Baldocchi, D. D., C. A. Vogel, and B. Hall (1997), Seasonal variation of energy and water vapor exchange rates above and below a boreal jack pine forest canopy, J. Geophys. Res., 102(D24), 28,939-28,951, doi:10.1029/96JD03325.

Baldocchi, D. D., L. Xu, and N. Kiang (2004), How plant functional-type, weather, seasonal drought, and soil physical properties alter water and energy fluxes of an oak-grass savanna and an annual grassland, Agric. For. Meteorol., 123, 13-39.

Billesbach, D. P., and T. J. Arkebauer (2012), First long-term, direct measurements of evapotranspiration and surface water balance in the Nebraska SandHills, Agric. For. Meteorol., 156, 104-110.

Blanken, P. D. (2014), The effect of winter drought on evaporation from a high-elevation wetland, J. Geophys. Res. Biogeosci., 119, 1354-1369, doi:10.1002/2014JG002648.

Bouchet, R. J. (1963), Evapotranspiration réelle et potentielle, signification climatique, Int. Assoc. Sci. Hydrol. Publ., 62, 134-142.

Brümmer, C., et al. (2012), How climate and vegetation type influence evapotranspiration and water use efficiency in Canadian forest, peatland and grassland ecosystems, Agric. For. Meteorol., 153, 14-30.

Brutsaert, W. (1982), Evaporation Into the Atmosphere: Theory, History and Applications, 299 pp., Springer, New York.

Brutsaert, W. (2013), Use of pan evaporation to estimate terrestrial evaporation trends: The case of the Tibetan Plateau, Water Resour. Res., 49, 3054-3058, doi:10.1002/wrcr.20247.

Brutsaert, W., and H. Stricker (1979), An advection-aridity approach to estimate actual regional evapotranspiration, Water Resour. Res., 15(2), 443-450, doi:10.1029/WR015i002p00443.

Burba, G. (2013), Eddy Covariance Method for Scientific, Industrial, Agricultural and Regulatory Applications: A Field Book on Measuring Ecosystem Gas Exchange and Areal Emission Rates, 330 pp., LI-COR Biosciences, Lincoln, NE.

Chiew, F. H. S., and C. P. Leahy (2003), Comparison of evapotranspiration variables in evapotranspiration maps for Australia with commonly used evapotranspiration variables, Aust. J. Water Res., 7(1), 1-11.

Crago, R., and R. Qualls (2013), The value of intuitive concepts in evaporation research, Water Resour. Res., 49, 6100-6104, doi:10.1002/ wrcr.20420.

Crago, R., R. Qualls, and M. Feller (2010), A calibrated advection-aridity evaporation model requiring no humidity data, Water Resour. Res., 46, W09519, doi:10.1029/2009WR008497. 
Drexler, J., R. Snyder, D. Spano, and K. T. Paw U (2004), A review of models and micrometeorological methods used to estimate wetland evapotranspiration, Hydrol. Process., 18, 2071-2101.

Falge, E., et al. (2001), Gap filling strategies for long term energy flux data sets, Agric. For. Meteorol., 107, 71-77.

Fischer, M., M. Trnka, J. Kučera, G. Deckmyn, M. Orság, P. Sedlák, Z. Žalud, and R. Ceulemans (2013), Evapotranspiration of a high-density poplar stand in comparison with a reference grass cover in the Czech-Moravian Highlands, Agric. For. Meteorol., 181, 43-60.

Foken, T. (2008), Micrometeorology, 308 pp., Springer, Heidelberg.

Gao, Y., X. Li, L. Ruby Leung, D. Chen, and J. Xu (2015), Aridity changes in the Tibetan Plateau in a warming climate, Environ. Res. Lett., 10(3), doi:10.1088/1748-9326/10/3/034013.

Granger, R. J. (1989), A complementary relationship approach for evaporation from nonsaturated surfaces, J. Hydrol., 111, 31-38.

Granger, R. J., and D. M. Gray (1990), Examination of Morton's CRAE model for estimating daily evaporation from field-sized areas, J. Hydrol., 120, 309-325.

Han, S., H. Hu, D. Yang, and F. Tian (2011), A complementary relationship evaporation model referring to the Granger model and the advection-aridity model, Hydrol. Process., 25, 2094-2101.

Han, S., H. Hu, and F. Tian (2012), A nonlinear function approach for the normalized complementary relationship evaporation model, Hydrol. Process., 26, 3973-3981.

Han, S., F. Tian, and H. Hu (2014a), Positive or negative correlation between actual and potential evaporation? Evaluating using a nonlinear complementary relationship model, Water Resour. Res., 50, 1322-1336, doi:10.1002/2013WR014151.

Han, S., D. Xu, S. Wang, and Z. Yang (2014b), Similarities and differences of two evapotranspiration models with routinely measured meteorological variables: Application to a cropland and grassland in northeast China, Theor. Appl. Climatol., 117, $501-510$.

Hobbins, M. T., J. A. Ramírez, and T. C. Brown (2001a), The complementary relationship in estimation of regional evapotranspiration: An enhanced Advection-Aridity model, Water Resour. Res., 37(5), 1389-1403, doi:10.1029/2000WR900359.

Hobbins, M. T., J. A. Ramírez, T. C. Brown, and L. H. J. M. Claessens (2001b), The complementary relationship in estimation of regional evapotranspiration: The complementary relationship areal evapotranspiration and advection-aridity models, Water Resour. Res., 37(5), 1367-1387, doi:10.1029/2000WR900358.

Hong, J., and J. Kim (2010), Numerical study of surface energy partitioning on the Tibetan Plateau: Comparative analysis of two biosphere models, Biogeosciences, 7, 557-568.

Huntington, J. L., J. Szilagyi, S. W. Tyler, and G. M. Pohll (2011), Evaluating the complementary relationship for estimating evapotranspiration from arid shrublands, Water Resour. Res., 47, W05533, doi:10.1029/2010WR009874.

Jaksa, W. T., V. Sridhar, J. L. Huntington, and M. Khanal (2013), Evaluation of the complementary relationship using Noah land surface mode and North American Regional Reanalysis (NARR) data to estimate evapotranspiration in semiarid ecosystems, J. Hydrometeorol., 14(1), 345-359.

Kabat, P., A. J. Dolman, and J. A. Elbers (1997), Evaporation, sensible heat and canopy conductance of fallow savannah and patterned woodland in the Sahel, J. Hydrol., 188-189, 494-515.

Kahler, D. M., and W. Brutsaert (2006), Complementary relationship between daily evaporation in the environment and pan evaporation, Water Resour. Res., 42, W05413, doi:10.1029/2005WR004541.

Katerji, N., and A. Perrier (1983), Modélisation de l'évapotranspiration réelle ETR d'une parcelle de luzerne: Rôle d'un coefficient cultural, Agronomie, 3, 513-521.

Katerji, N., and G. Rana (2006), Modelling evapotranspiration of six irrigated crops under Mediterranean climate conditions, Agric. For. Meteorol., 138, 142-155.

Katerji, N., G. Rana, and S. Fahed (2011), Parameterizing canopy resistance using mechanistic and semi-empirical estimates of hourly evapotranspiration: Critical evaluation for irrigated crops in the Mediterranean, Hydrol. Process., 25(1), 117-129.

Katul, G. G., R. Oren, S. Manzoni, C. Higgins, and M. B. Parlange (2012), Evapotranspiration: A process driving mass transport and energy exchange in the soil-plant-atmosphere-climate system, Rev. Geophys., 50, RG3002, doi:10.1029/2011RG000366.

Koike, T. (1999), GAME-Tibet IOP summary report paper presented at 1st International Workshop on GAME-Tibet, Xi'an, China.

Koike, T. (2004), The Coordinated Enhanced Observing Period-An initial step for integrated global water cycle observation, WMO Bull., 53(2), 115-121.

Kurc, S. A., and E. E. Small (2004), Dynamics of evapotranspiration in semiarid grassland and shrubland ecosystems during the summer monsoon season, central New Mexico, Water Resour. Res., 40, W09305, doi:10.1029/2004WR003068.

Lecina, S., A. Martínez-Cob, P. J. Pérez, F. J. Villalobos, and J. J. Baselga (2003), Fixed versus variable bulk canopy resistance for reference evapotranspiration estimation using the Penman-Monteith equation under semiarid conditions, Agric. Water Manage., 60(3), 181-198.

Legates, D. R., and G. J. McCabe (1999), Evaluating the use of "goodness-of-fit" measures in hydrologic and hydroclimatic model validation, Water Resour. Res., 35(1), 233-241, doi:10.1029/1998WR900018.

Leydecker, A., and J. Melack (2000), Estimating evaporation in seasonally snow-covered catchments in the Sierra Nevada, California, J. Hydrol., 236(1), 121-138.

$\mathrm{Li}, \mathrm{C}$, and M. Yanai (1996), The onset and interannual variability of the Asian summer monsoon in relation to land-sea thermal contrast J. Clim., 9(2), 358-375.

Li, X., L. Wang, D. Chen, K. Yang, and A. Wang (2014), Seasonal evapotranspiration changes (1983-2006) of four large basins on the Tibetan Plateau, J. Geophys. Res. Atmos., 119, 13,079-13,095, doi:10.1002/2014JD022380.

Liu, G., Y. Liu, M. Hafeez, D. Xu, and C. Vote (2012), Comparison of two methods to derive time series of actual evapotranspiration using eddy covariance measurements in the southeastern Australia, J. Hydrol., 454-455, 1-6.

Liu, S., R. Sun, Z. Sun, X. Li, and C. Liu (2006), Evaluation of three complementary relationship approaches for evapotranspiration over the Yellow River basin, Hydrol. Process., 20(11), 2347-2361.

Long, D., V. P. Singh, and Z. L. Li (2011), How sensitive is SEBAL to changes in input variables, domain size and satellite sensor?, J. Geophys. Res., 116, D21107, doi:10.1029/2011JD016542.

Ma, N., N. Wang, L. Zhao, Z. Zhang, C. Dong, and S. Shen (2014), Observation of mega-dune evaporation after various rain events in the hinterland of Badain Jaran Desert, China, Chin. Sci. Bull., 59(2), 162-170.

Ma, N., Y. Zhang, J. Szilagyi, Y. Guo, J. Zhai, and H. Gao (2015), Evaluating the complementary relationship of evapotranspiration in the alpine steppe of the Tibetan Plateau, Water Resour. Res., 51, 1069-1083, doi:10.1002/2014WR015493.

Ma, Y., M. Menenti, R. Feddes, and J. Wang (2008), Analysis of the land surface heterogeneity and its impact on atmospheric variables and the aerodynamic and thermodynamic roughness lengths, J. Geophys. Res., 113, D08113, doi:10.1029/2007JD009124.

Mackay, D. S., B. E. Ewers, B. D. Cook, and K. J. Davis (2007), Environmental drivers of evapotranspiration in a shrub wetland and an upland forest in northern Wisconsin, Water Resour. Res., 43, W03442, doi:10.1029/2006WR005149. 
Malek, E., and G. E. Bingham (1993), Comparison of the Bowen ratio-energy balance and the water balance methods for the measurement of evapotranspiration, J. Hydrol., 146, 209-220.

Matheny, A. M., et al. (2014), Characterizing the diurnal patterns of errors in the prediction of evapotranspiration by several land-surface models: An NACP analysis, J. Geophys. Res. Biogeosci., 119, 1458-1473, doi:10.1002/2014JG002623.

Mauder, M., and T. Foken (2004), Documentation and instruction manual of the eddy-covariance software package TK3 Universität Bayreuth, Abt Mikrometeorologie.

McMahon, T. A., M. C. Peel, L. Lowe, R. Srikanthan, and T. R. McVicar (2013), Estimating actual, potential, reference crop and pan evaporation using standard meteorological data: A pragmatic synthesis, Hydrol. Earth Syst. Sci., 17(4), 1331-1363.

McNaughton, K. G., and T. W. Spriggs (1986), A mixed-layer model for regional evaporation, Bound. Layer Meteorol., 34, $243-262$.

Monteith, J. L. (1965), Evaporation and environment paper presented at 19th Symposium of the Society for Experimental Biology, Cambridge Univ. Press, New York.

Morton, F. I. (1983), Operational estimates of areal evapotranspiration and their significance to the science and practice of hydrology, J. Hydrol., 66, 1-76.

Oki, T., and S. Kanae (2006), Global hydrological cycles and world water resources, Science, 313(5790), 1068-1072.

Oliphant, A. J., C. S. B. Grimmond, H. N. Zutter, H. P. Schmid, H. B. Su, S. L. Scott, B. Offerle, J. C. Randolph, and J. Ehman (2004), Heat storage and energy balance fluxes for a temperate deciduous forest, Agric. For. Meteorol., 126, 185-201.

Ozdogan, M., and G. D. Salvucci (2004), Irrigation-induced changes in potential evapotranspiration in southeastern Turkey: Test and application of Bouchet's complementary hypothesis, Water Resour. Res., 40, W04301, doi:10.1029/2003WR002822.

Pauwels, V. R. N., and R. Samson (2006), Comparison of different methods to measure and model actual evapotranspiration rates for a wet sloping grassland, Agric. Water Manage., 82, 1-24.

Penman, H. L. (1948), Natural evaporation from open water, bare soil and grass, Proc. R. Soc. London, Ser. A, 193, 120-145, doi:10.1098/ rspa.1948.0037.

Perez, P. J., F. Castellvi, M. Ibanez, and J. I. Rosell (1999), Assessment of reliability of Bowen ratio method for partitioning fluxes, Agric. For. Meteorol., 97(3), 141-150.

Perrier, A. (1975), Etude de l'évapotranspiration dans les conditions naturelles. I. Evaporation et bilan d'energie des surface naturelles, Ann Agron., 26, 1-18.

Pettijohn, J. C., and G. D. Salvucci (2009), A new two-dimensional physical basis for the complementary relation between terrestrial and pan evaporation, J. Hydrometeorol., 10(2), 565-574.

Priestley, C. H. B., and R. J. Taylor (1972), On the assessment of surface heat flux and evaporation using large-scale parameters, Mon. Weather Rev., 100(2), 81-92.

Prueger, J. H., J. L. Hatfield, J. K. Aase, and J. L. Pikul (1997), Bowen-ratio comparisons with lysimeter evapotranspiration, Agron. J., 89(5), 730-736.

Qiu, J. (2008), China: The third pole, Nature, 454(7203), 393-396.

Rana, G., and N. Katerji (2008), Direct and indirect methods to simulate the actual evapotranspiration of an irrigated overhead table grape vineyard under Mediterranean conditions, Hydrol. Process., 22(2), 181-188.

Rana, G., N. Katerji, M. Mastrorillia, and M. Moujabberc (1997), A model for predicting actual evapotranspiration under soil water stress in a Mediterranean region, Theor. Appl. Climatol., 56, 45-55.

Rana, G., N. Katerji, and M. Perniola (2001), Evapotranspiration of sweet sorghum: A general model and multilocal validity in semiarid environmental conditions, Water Resour. Res., 37(12), 3237-3246, doi:10.1029/2001WR000476.

Rana, G., N. Katerji, and F. de Lorenzi (2005), Measurement and modelling of evapotranspiration of irrigated citrus orchard under Mediterranean conditions, Agric. For. Meteorol., 128(3-4), 199-209.

Reichstein, M., et al. (2005), On the separation of net ecosystem exchange into assimilation and ecosystem respiration: Review and improved algorithm, Global Change Biol., 11(9), 1424-1439.

Rigden, A., and G. Salvucci (2015), Evapotranspiration based on equilibrated relative humidity (ETRHEQ): Evaluation over the continental United States, Water Resour. Res., 51, 2951-2973, doi:10.1002/2014WR016072.

Ryu, Y., D. D. Baldocchi, S. Ma, and T. Hehn (2008), Interannual variability of evapotranspiration and energy exchange over an annual grassland in California, J. Geophys. Res., 113, D09104, doi:10.1029/2007JD009263.

Saigusa, N., T. Oikawa, and S. Liu (1998), Seasonal variations of the exchange of $\mathrm{CO}_{2}$ and $\mathrm{H}_{2} \mathrm{O}$ between a grassland and the atmosphere: An experimental study, Agric. For. Meteorol., 89, 131-139.

Savage, M. J. (2010), Field evaluation of polymer capacitive humidity sensors for Bowen ratio energy balance flux measurements, Sensors, 10 , 7748-7771.

Sellers, P. J., et al. (1997), Modeling the exchanges of energy, water, and carbon between continents and the atmosphere, Science, 275(5299), 502-509.

Shen, M., Z. Sun, S. Wang, G. Zhang, W. Kong, A. Chen, and S. Piao (2013), No evidence of continuously advanced green-up dates in the Tibetan Plateau over the last decade, Proc. Natl. Acad. Sci. U.S.A., 110(26), doi:10.1073/pnas.1304625110.

Shen, M., G. Zhang, N. Cong, S. Wang, W. Kong, and S. Piao (2014), Increasing altitudinal gradient of spring vegetation phenology during the last decade on the Qinghai-Tibetan Plateau, Agric. For. Meteorol., 189-190, 71-80.

Shi, T., D. Guan, A. Wang, J. Wu, C. Jin, and S. Han (2008), Comparison of three models to estimate evapotranspiration for a temperate mixed forest, Hydrol. Process., 22(17), 3431-3443.

Shuttleworth, W. J. (2007), Putting the 'vap' into evaporation, Hydrol. Earth Syst. Sci., 11(1), 201-244.

Steduto, P., M. Todorovic, A. Caliandro, and P. Rubino (2003), Daily reference evapotranspiration estimates by the Penman-Monteith equation in Southern Italy. Constant vs. variable canopy resistance, Theor. Appl. Climatol., 74(3-4), 217-225.

Szilagyi, J. (2007), On the inherent asymmetric nature of the complementary relationship of evaporation, Geophys. Res. Lett., 34, L02405, doi:10.1029/2006GL028708.

Szilagyi, J. (2014), Temperature corrections in the Priestley-Taylor equation of evaporation, J. Hydrol., 519, 455-464.

Szilagyi, J., and J. Jozsa (2008), New findings about the complementary relationship-based evaporation estimation methods, J. Hydrol., 354(1-4), 171-186.

Szilagyi, J., G. G. Katul, and M. B. Parlange (2001), Evapotranspiration intensifies over the conterminous United States, J. Water Res. Plann. Man., 127(6), 361-370.

Szilagyi, J., M. T. Hobbins, and J. Jozsa (2009), Modified advection-aridity model of evapotranspiration, J. Hydrol. Eng., 14(6), 569-574.

Szilagyi, J., M. B. Parlange, and G. G. Katul (2014), Assessment of the Priestley-Taylor parameter value from ERA-Interim global reanalysis data, J. Hydrol. Environ. Res., 2(1), 1-7. 
Tian, L., T. Yao, W. Sun, M. Stievenard, and J. Jouzel (2001), Relationship between $\delta \mathrm{D}$ and $\delta^{18} \mathrm{O}$ in precipitation on north and south of the Tibetan Plateau and moisture recycling, Sci China Ser D Earth Sci., 44(9), 789-796.

Timmermans, W. J., W. P. Kustas, M. C. Anderson, and A. N. French (2007), An intercomparison of the Surface Energy Balance Algorithm for Land (SEBAL) and the Two-Source Energy Balance (TSEB) modeling schemes, Remote Sens. Environ., 108(4), 369-384.

Todorovic, M. (1999), Single-layer evapotranspiration model with variable canopy resistance, J. Irrig. Drain. Eng., 125, 235-245.

Trenberth, K. E., J. T. Fasullo, and J. Kiehl (2009), Earth's global energy budget, Bull. Am. Meteorol. Soc., 90(3), 311-323.

Unland, H. E., P. R. Houser, W. J. Shuttleworth, and Z. L. Yang (1996), Surface flux measurement and modeling at a semi-arid Sonoran Desert site, Agric. For. Meteorol., 82, 119-153.

Wang, K., and R. E. Dickinson (2012), A review of global terrestrial evapotranspiration: Observation, modeling, climatology, and climatic variability, Rev. Geophys., 50, RG2005, doi:10.1029/2011RG000373.

Wang, W., W. Xing, Q. Shao, Z. Yu, S. Peng, T. Yang, B. Yong, J. Taylor, and V. P. Singh (2013), Changes in reference evapotranspiration across the Tibetan Plateau: Observations and future projections based on statistical downscaling, J. Geophys. Res. Atmos., 118, 4049-4068, doi:10.1002/jgrd.50393.

Wang, Y., B. Liu, B. Su, J. Zhai, and M. Gemmer (2011), Trends of calculated and simulated actual evaporation in the Yangtze River basin, J. Clim., 24(16), 4494-4507.

Wever, L. A., L. B. Flanagan, and P. J. Carlson (2002), Seasonal and interannual variation in evapotranspiration, energy balance and surface conductance in a northern temperate grassland, Agric. For. Meteorol., 112, 31-49.

Wilson, K. B., and D. D. Baldocchi (2000), Seasonal and interannual variability of energy fluxes over a broadleaved temperate deciduous forest in North America, Agric. For. Meteorol., 100(1), 1-18.

$\mathrm{Xu}, \mathrm{C}$., and V. P. Singh (2005), Evaluation of three complementary relationship evapotranspiration models by water balance approach to estimate actual regional evapotranspiration in different climatic regions, J. Hydrol., 308, 105-121.

Yang, D., D. Kane, Z. Zhang, D. Legates, and B. Goodison (2005), Bias corrections of long-term (1973-2004) daily precipitation data over the northern regions, Geophys. Res. Lett., 32, L19501, doi:10.1029/2005GL024057.

Yang, F., and G. Zhou (2011), Characteristics and modeling of evapotranspiration over a temperate desert steppe in Inner Mongolia, China, J. Hydrol., 396, 139-147.

Yang, K., T. Koike, H. Ishikawa, J. Kim, X. Li, H. Liu, S. Liu, Y. Ma, and J. Wang (2008), Turbulent flux transfer over bare-soil surfaces: Characteristics and parameterization, J. Appl. Meteorol. Climatol., 47(1), 276-290.

Yang, K., Y. Chen, and J. Qin (2009), Some practical notes on the land surface modeling in the Tibetan Plateau, Hydrol. Earth Syst. Sci., 13, 687-701.

Yang, K., B. Ye, D. Zhou, B. Wu, T. Foken, J. Qin, and Z. Zhou (2011), Response of hydrological cycle to recent climate changes in the Tibetan Plateau, Clim. Change, 109(3-4), 517-534.

Yang, Y., J. Fang, Y. Pan, and C. Ji (2009), Aboveground biomass in Tibetan grasslands, J. Arid Environ., 73(1), 91-95.

Yao, T., J. Pu, A. Lu, Y. Wang, and W. Yu (2007), Recent glacial retreat and its impact on hydrological processes on the Tibetan Plateau, China, and surrounding regions, Arctic Antarct. Alp. Res., 39(4), 642-650.

Yao, T., et al. (2012), Different glacier status with atmospheric circulations in Tibetan Plateau and surroundings, Nat. Clim. Change, 2, 663-667.

Yao, T., et al. (2013), A review of climatic controls on $\delta^{18} \mathrm{O}$ in precipitation over the Tibetan Plateau: Observations and simulations, Rev. Geophys., 51, 525-548, doi:10.1002/rog.20023.

Ye, B., D. Yang, Y. Ding, T. Han, and T. Koike (2004), A bias-corrected precipitation climatology for China, J. Hydrometeorol, 5, 1147-1160.

Ye, D., and G. Wu (1998), The role of the heat source of the Tibetan Plateau in the general circulation, Meteorol. Atmos. Phys., 67, 181-198.

Yin, Y., S. Wu, D. Zhao, D. Zheng, and T. Pan (2013a), Modeled effects of climate change on actual evapotranspiration in different eco-geographical regions in the Tibetan Plateau, J. Geogr. Sci., 23(2), 195-207.

Yin, Y., S. Wu, and D. Zhao (2013b), Past and future spatiotemporal changes in evapotranspiration and effective moisture on the Tibetan Plateau, J. Geophys. Res. Atmos., 118, 10,850-10,860, doi:10.1002/jgrd.50858.

Zenone, T., M. Fischer, N. Arriga, L. S. Broeckx, M. S. Verlinden, S. Vanbeveren, D. Zona, and R. Ceulemans (2015), Biophysical drivers of the carbon dioxide, water vapor, and energy exchanges of a short-rotation poplar coppice, Agric. For. Meteorol., 209, 22-35.

Zhang, Q., S. Manzoni, G. Katul, A. Porporato, and D. Yang (2014), The hysteretic evapotranspiration-Vapor pressure deficit relation, J. Geophys. Res. Biogeosci., 119, 125-140.

Zhang, Y., C. Liu, Y. Tang, and Y. Yang (2007), Trends in pan evaporation and reference and actual evapotranspiration across the Tibetan Plateau, J. Geophys. Res., 112, D12110, doi:10.1029/2006JD008161.

Zheng, J., J. Bian, Q. Ge, Z. Hao, Y. Yin, and Y. Liao (2013), The climate regionalization in China for 1981-2010, Chin. Sci. Bull., 58, 3088-3099.

Zhong, L., Z. Su, Y. Ma, M. S. Salama, and J. A. Sobrino (2011), Accelerated changes of environmental conditions on the Tibetan Plateau caused by climate change, J. Clim., 24(24), 6540-6550.

Zhou, D., and R. Huang (2012), Response of water budget to recent climatic changes in the source region of the Yellow River, Chin. Sci. Bull., 57(17), 2155-2162. 